\title{
Remote sensing and spatial statistical techniques for modelling Ommatissus lybicus (Hemiptera: Tropiduchidae) habitat and population densities
}

\author{
Khalifa M Al-Kindi ${ }^{\text {Corresp., }}{ }^{1}$, Paul Kwan ${ }^{1}{ }^{,}$, Nigel Andrew ${ }^{2}$, Mitchell Welch ${ }^{1}$ \\ ${ }^{1}$ School of Science and Technology, University of New England, Armidale, NSW, Australia \\ 2 Centre for Excellence for Behavioural and Physiological Ecology, University of New England, Armidale, NSW, Australia \\ Corresponding Author: Khalifa M Al-Kindi \\ Email address: kalkindi@myune.edu.au
}

In order to understand the distribution and prevalence of Ommatissus lybicus (Hemiptera: Tropiduchidae) as well as analyse their current biographical patterns and predict their future spread, comprehensive and detailed information on the environmental, climatic, and agricultural practices are essential. The spatial analytical techniques such as Remote Sensing and Spatial Statistics Tools, can help detect and model spatial links and correlations between the presence, absence and density of $O$. lybicus in response to climatic, environmental and human factors. The main objective of this paper is to review remote sensing and relevant analytical techniques that can be applied in mapping and modelling the habitat and population density of $O$. lybicus. An exhaustive search of related literature revealed that there are very limited studies linking location-based infestation levels of pests like the $O$. lybicus with climatic, environmental and human practice related variables. This review also highlights the accumulated knowledge and addresses the gaps in this area of research. Furthermore, it makes recommendations for future studies, and gives suggestions on monitoring and surveillance methods in designing both local and regional level integrated pest management (IPM) strategies of palm tree and other affected cultivated crops. 
1 Remote sensing and spatial statistical techniques for modelling Ommatissus lybicus

2 (Hemiptera: Tropiduchidae) habitat and population densities

\section{Khalifa M. Al-Kindi ${ }^{1}$ *, Paul Kwan ${ }^{1}$ Nigel R. Andrew ${ }^{2}$ and Mitchell Welch ${ }^{1,}$}

41 School of Science and Technology, University of New England, Armidale, NSW 2351,

$5 \quad$ Australia; kalkindi@myune.edu.au (KA), paul.kwan@une.edu.au (PK) and

$6 \quad$ mwelch8@une.edu.au (MW)

$7 \quad 2$ Centre of Excellence Behavioural and Physiological Ecology, Natural History Museum

$8 \quad$ University of New England, Armidale, NSW 2351, Australia; nigel.andrew@une.edu.au

$9 \quad(\mathrm{NA})$

*Correspondence: kalkindi@myune.edu.au; Tel.: +61 267732034

Abstract: In order to understand the distribution and prevalence of Ommatissus lybicus (Hemiptera: Tropiduchidae) as well as analyse their current biographical patterns and predict their future spread, comprehensive and detailed information on the environmental, climatic, and agricultural practices are essential. The spatial analytical techniques such as Remote Sensing and Spatial Statistics Tools, can help detect and model spatial links and correlations between the presence, absence and density of $O$. lybicus in response to climatic, environmental and human factors. The main objective of this paper is to review remote sensing and relevant analytical techniques that can be applied in mapping and modelling the habitat and population density of O. lybicus. An exhaustive search of related literature revealed that there are very limited studies linking location-based infestation levels of pests like the O. lybicus with climatic, environmental and human practice related variables. This review also highlights the accumulated knowledge and addresses the gaps in this area of research. Furthermore, it makes 
23 recommendations for future studies, and gives suggestions on monitoring and surveillance

24 methods in designing both local and regional level integrated pest management (IPM) strategies

25 of palm tree and other affected cultivated crops.

\section{Abbreviations used in the paper}

28

29 AFRI

Aerosol Free Vegetation Index

30 ANN

Artificial neural network

31 AI

Artificial Intelligence

32 ASTER

Advanced Space Thermal Emission and Reflection Radiometer

33 AVHRR

Advanced Very High Resolution Radiometer

34 AVIRIS

Airborne Visible/Infrared Imaging Spectrometer

35 ALOS

Advanced Land Observing Satellite

36 AC

Atmospheric correction

37 ARVI

Atmospherically Resistant Vegetation Index

38 BIO

Bare soil index

39 CA

Cellular Automata

40 CART

Classification and regression tree

41 CIR

Colour-infrared

42 DEM

Digital Elevation Model

43 DB

Dubas Bug

44 DVI

Different vegetation index

45 NDV

Normalized different vegetation

46 NDMI

Normalisation different moisture index

$47 \quad$ FS

Fluorescence spectroscopy

48 GIS

Geographical Information Systems

49 GEMI

Global Environmental Monitoring Index

50 GR

Geometrical rectification

51 GWR

Geographically Weighted Regression

52 HTR

Humid-Thermal Ratio

53 IPM

Integrated Pest Management

54 IR

Image registration

55 LIDAR

Light detection and ranging

56 LAI

Leaf area index 


\begin{tabular}{|c|c|c|}
\hline 57 & LWCI & Leaf water content index \\
\hline 58 & MIR & Mid-infrared \\
\hline 59 & MODIS & Moderate Resolution Imaging Spectroradiometer \\
\hline 60 & MAS & Multi-agent system \\
\hline 61 & MNF & Minimum noise fraction \\
\hline 62 & MSS & Multi-Spectral Scanner \\
\hline 63 & NAIP & National Agricultural Imagery Programme \\
\hline 64 & NIR & Near-infrared \\
\hline 65 & OBIA & Object-based image analysis \\
\hline 66 & PCA & Principal Components Analysis \\
\hline 67 & PVI & Perpendicular Vegetation Index \\
\hline 68 & REPD & Red-edge position determination \\
\hline 69 & RS & Remote Sensing \\
\hline 70 & RVI & Ratio vegetation Index \\
\hline 71 & SAVI & Soil adjusted vegetation \\
\hline 72 & SCI & Shadow canopy index \\
\hline 73 & SPOT & Satellite Probatoire l'Observation de la Terre \\
\hline 74 & SVM & Support vector machines \\
\hline 75 & $\mathrm{TM}$ & Thematic Mapper \\
\hline 76 & $\mathrm{TC}$ & Topographic correction \\
\hline 77 & UAV & Unmanned aerial vehicle \\
\hline 78 & VIS & Visible \\
\hline 79 & VI & Vegetation Indices \\
\hline م & & \\
\hline & & \\
\hline
\end{tabular}


83

84

85

86

87

\section{Introduction}

Remote sensing (RS) is a powerful technology that has been applied in precision agriculture applications (Shah et al. 2013). Remotely sensed data can be used in mapping tools to classify crops and examine their health and viability. They can also be used for monitoring farming practices and to measure soil moisture across a wide area instead of at discrete point locations that are inherent to ground measurement (Atzberger 2013). Based on these spatial differences, variable rate application of chemicals such as fertilisers or pesticides can be made. Remote sensing information can further be used to establish sub-field management zones, providing a less expensive yet finer resolution option than grid sampling.

Although RS technologies are more widely used in other industries, their potential for profitable use by farmers is less frequently studied. As examples in agriculture, RS technologies have been used successfully for monitoring and mapping water stress, crop quality and growth, wetland, water quality, phosphorus and nitrogen deficiencies in vegetation, as well as detecting and predicting insect infestations (e.g. O. lybicus)(Al-Kindi et al. 2017a) and plant diseases (; Neteler et al. 2011).

\subsection{Background}

The date palm, Phoenix dactylifera Linnaeus, is an important economic resource in the Sultanate of Oman. Plant-parasitic nematodes, associated with date palm trees in Oman and in most other Arab countries, can reduce their economic yields (El-Juhany 2010). A variety of insect pests can cause major damages to this crop through production losses and plant death (Abdullah et al. 2010; Al-Khatri 2004; Blumberg 2008; El-Shafie 2012; Howard 2001). One such species, Ommatissus lybicus de Bergevin 1930 (Hemiptera: Tropiduchidae), which is known more commonly as Dubas bug (DB), has been identified as a major economic threat, and is presently 
106 affecting palm growth yield in Oman (Al-Yahyai 2006). Indeed, the DB has been identified as

107 one of the primary reasons for the decline in date production in Oman (Al-Yahyai \& Al-Khanjari

108 2008; Al-Zadjali et al. 2006; Mamoon et al. 2016). It is also a principal pest of date palms in

109 many locations throughout the Middle East, East and North Africa, (Klein \& Venezian 1985;

110 Mifsud et al. 2010). The DB is believed to have been introduced into the Tigris-Euphrates River

111 Valley, from where it has spread to other zones in recent decades (Blumberg 2008; El-Haidari et

112 al. 1968).

113 The DB is a sap feeding insect; both adults and nymphs suck the sap from date palms, thereby

114 causing chlorosis (removal of photosynthetic cells and yellowing of fronds). Prolonged high

115 infestation level will result in the flagging and destruction of palm plantations (Al-Khatri 2004;

116 Howard 2001; Hussain 1963; Mahmoudi et al. 2015; Mokhtar \& Al Nabhani 2010; Shah et al.

117 2013). There is also an indirect effect whereby honeydew secretions produced by the DB can

118 promote the growth of black sooty mould on the foliage and consequently a reduction in the

119 photosynthetic rates of date palms (Blumberg 2008; Mokhtar \& Al-Mjeini 1999; Shah et al.

120 2012). Nymphs pass through five growth instars (Hussain 1963; Shah et al. 2012), with adult

121 female DB reaching 5-6 $\mathrm{mm}$ and the males 3-3.5 $\mathrm{mm}$ in length (Aldryhim 2004; Mokhtar \& Al

122 Nabhani 2010). Their colour is yellowish-green while the main distinguishing feature between

123 males and females is the presence of spots on females; males have a more tapered abdomen and

124 larger wings relative to the abdomen (Al-Azawi 1986; Al-Mahmooli et al. 2005; Elwan \& Al-

125 Tamimi 1999; Hussein \& Ali 1996; Jasim \& Al-Zubaidy 2010; Kaszab et al. 1979; Khalaf et al.

126 2012; Mokhtar \& Al Nabhani 2010; Thacker et al. 2003).

127 1.2. Study Area 
128 The Sultanate of Oman, which covers an area of $309,500 \mathrm{~km}^{2}$, extends from $16^{\circ} 40^{\prime} \mathrm{N}$ to $26^{\circ} 20^{\prime} \mathrm{N}$,

129 and 51 $50^{\prime}$ 'E to 59 $40^{\prime}$ E. It occupies the south-eastern corner of the Arabian Peninsula (Figure 1).

130 It has 3,165 km of coastline, extending from the Strait of Hormuz in the north to the border with

131 the Republic of Yemen in the South. The coastline faces onto three different water bodies, 132 namely the Arabian Sea, the Persian Gulf (also known as Arabian Gulf), and the Gulf of Oman.

133 To the west, Oman is bordered by the United Arab Emirates and the Kingdom of Saudi Arabia.

134 Mountainous areas account for $15 \%$ of the land area, while desert plains and sandy areas cover

$13574 \%$, agro-biodiversity areas cover $8 \%$, and the coastal zone covers $3 \%$, respectively (Luedeling

$136 \&$ Buerkert 2008). The location of Oman provides favourable conditions for agriculture, with

137 land under agricultural use accounting for $8 \%$ of the territory and the economic output

138 accounting for $14.6 \%$ of the GDP in 2008. According to the 2004-2005 soil survey conducted by

139 the Ministry of Food and Agricultural (MFA), 22,230 km² (equivalent 2.223 million ha) is

140 optimal for agricultural activity, which represents $\sim 7.5 \%$ of the country's land area.

141 Approximately $728.2 \mathrm{~km}^{2}(\sim 72,820 \mathrm{ha})$ of the country is irrigated using the falaj irrigation

142 system, where local springs or wadis (streams) underflow areas are cultivated with palm trees,

143 banana, limes, alfalfa, and vegetables (Gebauer et al. 2007).

144 Oman has an arid climate, receiving less than $100 \mathrm{~mm}$ of rainfall per year; however, the mountainous 145 parts of the country receive higher precipitation levels (Kwarteng et al. 2009). As the dependent variable, 146 DB infestations occur where palm trees are concentrated; therefore, in this study we focused on northern 147 Oman $\left(26^{\circ} 50 \mathrm{~N}\right.$ to $22^{\circ} 26 \mathrm{~N}$, and $55^{\circ} 50^{\prime} \mathrm{E}$ to $\left.59^{\circ} 50 \mathrm{E}\right)$ which experiences high infestations (Figure 1)(Al148 Kindi et al. 2017b).

149 Dubas bugs are active on leaflets, rachis, fruiting bunches and spines during different stages of 150 growth of date palm trees. These infestations are capable of causing up to $50 \%$ crop loss during a 
151 heavy infestation (Shah et al. 2013). Studies of insect pest of date tree palm indicated more than

15254 arthropods species insects connected with date plantations. Nevertheless, DB and red weevil

153 (RPW) Rhynchophorusferrugineus Oliver, and lesser moth, are considered major economically

154 significant pests affecting growth and yield of date palm trees (Al-Zadjali et al. 2006).

155

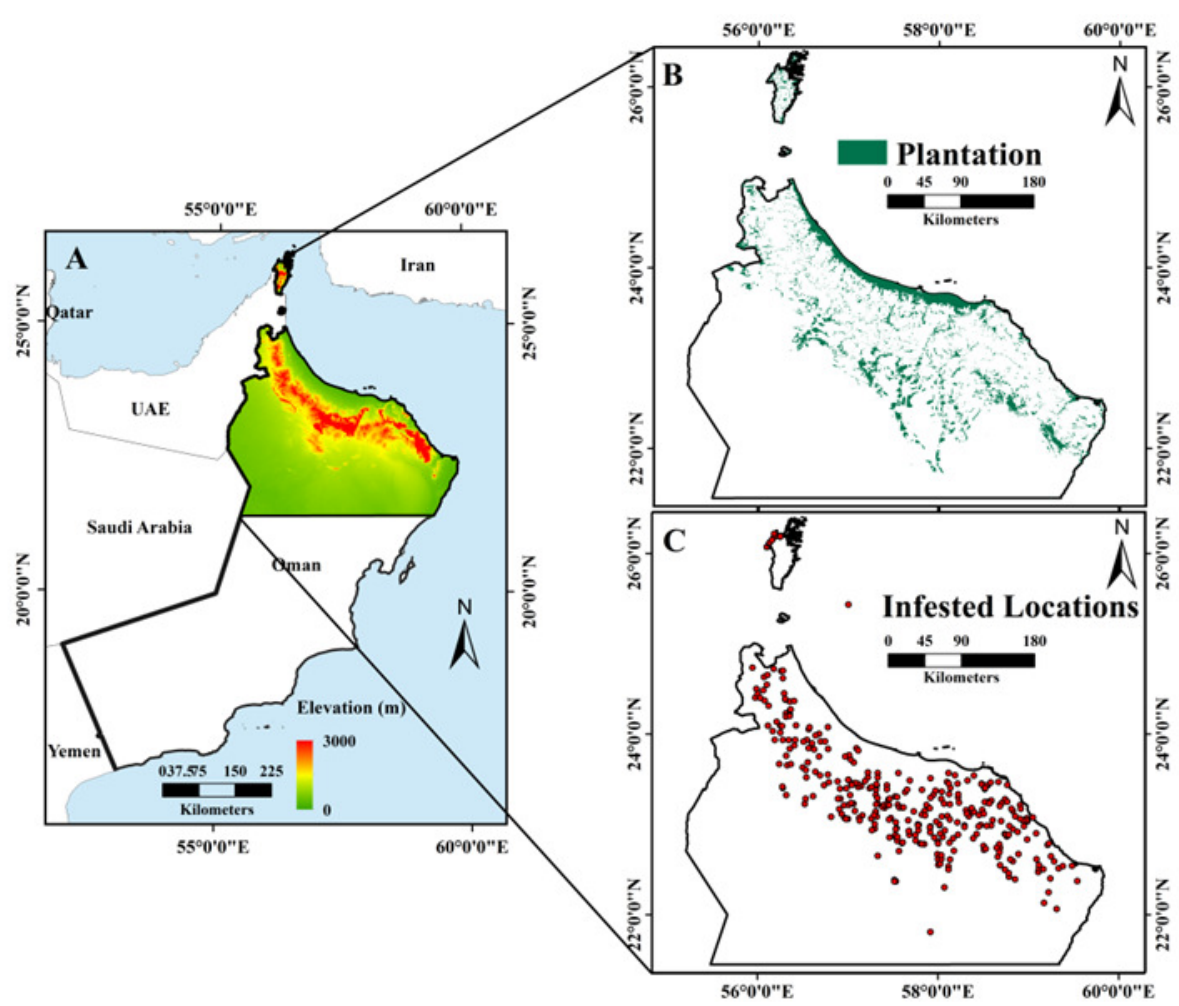

156

157 Fig 1: Maps of the study area, including: (A) topography and location of Oman, with the study 158 area outlined by the black rectangle; (B) elevation change within the study area; and (C) 159 distribution of date palm plantations in the study area (Esri ArcGIS 10.3). 
161 The biology of this species has been investigated in a number of studies (Al-Azawi 1986;

162 Arbabtafti et al. 2014; Hussain 1963; Jasim \& Al-Zubaidy 2010; Klein \& Venezian 1985;

163 Payandeh \& Dehghan 2011; Shah et al. 2012). The DB produces two generations annually,

164 including the spring and autumn generations (Blumberg 2008; Hussain 1963). In the spring

165 generation, eggs start hatching from February to April, after which nymphs pass through five

166 instars to become adults in approximately 6-7 weeks. The eggs aestivate during the hot season

167 (i.e., summer) until the autumn generation, when they start hatching from late August to the last

168 week of October. A nymph takes about 6 weeks to develop into an adult, which then lives for 169 about 12 weeks. Females lay between 100 and 130 eggs (Elwan \& Al-Tamimi 1999; Mokhtar \&

170 Al Nabhani 2010).The female DB lays her eggs by inserting them into holes in the tissue of the

171 date palm frond at the end of each generation. The eggs remain dormant for about three months.

172 When they hatch, the resulting nymphs remain on the fronds of the same tree, feeding on the sap

173 and defecating large amounts of honeydew, which eventually covers the palm fronds and

174 promotes the growth of black sooty mould(Zamani et al. 2013).

175 In extreme cases, the sooty mould that develops from the honeydew secretions can block the

176 stomata of the leaves, causing partial or complete suffocation of the date palm, which in turn

177 reduces its yield. The honeydew secretion also makes the dates unpalatable (Aminaee et al. 2010;

178 El-Juhany 2010; Gassouma 2004; Mamoon et al. 2016). The eggs of DB are sensitive to

179 temperature. In summer, the eggs can hatch within 18-21 days, but in winter they may take up to

180170 days to hatch (Blumberg 2008). The developmental time of DBs eggs has been studied at 181 three different temperatures, 17.6, 27.5 and $32.4{ }^{\circ} \mathrm{C}$ in Oman (Al-Khatri 2011). The results 182 showed that a temperature of $27.5^{\circ} \mathrm{C}$ appeared to be the optimal temperature for the biological 183 activities of this species (Al-Khatri 2011). At $35^{\circ} \mathrm{C}$, the biological processes of the pest are 
184 disrupted, thus leading to high mortality, particularly in females (Bagheri et al. 2016; Bedford et 185 al. 2015).

186 Investigations into the population and the fluctuation in spatial distribution (Khalaf \& Khudhair 187 2015) of the two DB generations in the Bam region of Iran showed that this pest has an 188 aggregated spatial distribution pattern (Payandeh et al. 2010). Seasonal activities effected by 189 climate change showed that nymphs were dynamic from April to May in the first generation and 190 August to October in the second generation. In the first and second generations, the adults are 191 active from May to June and from September to November, respectively. Earlier work 192 (Blumberg 2008) reported that temperature exposure below $0{ }^{\circ} \mathrm{C}$ adversely affects the ability of adults to survive. The DB avoids direct sunlight (Klein \& Venezian 1985; Shah et al. 2013), and

194 it is spread via the transfer of infested offshoots as well as by wind or wind dust (Hassan 2014; 195 Jasim \& Al-Zubaidy 2010).

\subsection{Biological Control}

197

198

199

200

201

202

203

204

205

206

Some research has also been conducted on the natural biological control of the DB, such as using predators and parasites. Early results showed a variety of natural predators that could be used as biological control agents, among these being Aprostocetus sp., Oligosita sp.and Runcinia sp.(Cammell \& Knight 1992). Furthermore, (Hussain 1963) reported that the eggs of the DB could be parasitized by a small Chalcidoid, while the nymphs and adults were preyed upon by the larvae of the lace wing (Chrysopa carnea Steph.). Hussain also stated three adult species of Coccinellids that prey on nymphs and adults of the DB. However, further study is needed to determine the distributions of these natural enemies in Oman and their effectiveness in controlling DB populations. Some measure of success was also achieved with pathogenic bacteria as microbiological control agents (Khudhair et al. 2016), although their toxicological 
207 aspects require further research in order to assess the safety of their implementation at a large

208 scale (Cannon 1998).

209

210

211

212

213

214

215

216

217

218

219

220

221

222

223

224

225

226

227

228

\subsection{Chemical Control}

Given the significant economic impact of this pest, research into effective management strategies demands high priority. Several insecticides have been evaluated for DB control in Oman since 1962 (Table 1) with SUMI-ALPHA ${ }^{\circledR} 5$ EC being effective as a ground spray and KARATE® 2 ULV, TREBON® $30 \mathrm{ULV}$ and SUMICOMBI ${ }^{\circledR} 50 \mathrm{ULV}$ achieving some measure of success as aerial sprays. KARATE-ZEON was also found to be very effective as it gave $100 \%$ reduction in numbers of DB instars and adults, between three and seven days after application. However, the use of this particular pesticide is restricted due to its side effects such as irritation (Al-Yahyai \& Khan 2015). In Israel, systemic carbamates such as aldicarb and butocarboxim have been successful, while in Iraq dichlorvos (DDVP) injected directly into the infected palms were also successful in suppressing the pest population (Blumberg 2008). Nonetheless, this method of control is expensive with negative environmental impacts on non-target species (particularly natural enemies of DB) as well as on human health.

Table 1. Major pesticides used in DB management in Oman

224 Research has shown that some pesticide residues persist in the fruit up to 60 days after application (Al-Samarrie \& Akela 2011). In addition, chemical control has achieved limited successes and DB continues to pose a major challenge to Omani agriculture. More information about the biological and chemical control and their impacts can be found in literature (Shifley et al. 2014; Thacker et al. 2003). 


\subsection{Research Opportunities}

230 A number of opportunities exist for research into the biology and ecology of this species in order

231 to gain a thorough understanding of its life cycle and its distribution. The climatic factors that

232 influence its survival and distribution also merit study because such information may be useful in

233 determining current and future potential distributions, particularly in light of climate change.

234 In a review of the effects of climate change on pest populations, an earlier report (Cammell \&

235 Knight 1992) suggested that increases in mean global temperatures, as well as changes in rainfall

236 and wind patterns, could have profound impacts on the population dynamics, abundance and

237 distribution of insect pests of agricultural crops. More recent research has supported this finding

238 (Bale et al. 2002; Cannon 1998; Cook 2008; Shifley et al. 2014; Tobin et al. 2014). A key issue

239 in ecology and conservation is the mapping of pest species distributions as this information can

240 be used to devise more effective management strategies for their control.

241 Mapping of DB infestations is important for developing predictive models that give the

242 probability of occurrence, spatial distributions and densities under different environmental,

243 meteorological, anthropogenic and resource availability conditions. Maps such as the DB hazard

244 map can be used to devise an Integrated Palm Management (IPM) plan, thus enhancing capacity

245 and educating farmers on how to apply IPM for the control of this pest.

246 Mapping DBs are also beneficial in terms of better planning of date palm orchard locations,

247 better design and management of farms, what cultivars to plant, distance between palms,

248 irrigations, pesticides, fertilisations, etc. There will also be savings in the cost of monitoring

249 since RS based techniques developed as parts of this study can provide a more efficient and cost-

250 effective means for large scale monitoring of infestations and observation of stress levels on date

251 palm trees. 
252 The aim of this review is to highlight technological advances in the fields of RS (i.e. by aircraft

253 or a satellite platform) and spatial statistical techniques that can be used to significantly enhance

254 our ability to detect and characterise physical and biological stresses on several plant species. In

255 particular, advanced RS and spatial statistical techniques need to be developed and implemented

256 for the surveillance and control of DB adults and nymphs over large spatial scales. In turn, this

257 will greatly assist Plant Protection Service (PPS) projects, Integrated Pest Management

258 Technology (IPMT) programs and farmers in protecting their palm tree orchards by adopting 259 timely preventative actions.

260 2. Remote Sensing Data

\subsection{Data Requirements for Crop Management}

262 It is important to collect data regarding crops and soil and to identify the changes that occur in

263 the field to achieve precise crop management in the agricultural sector. Data are needed on the

264 conditions that are stable across seasons (e.g. crop type, soil fertility), differing during the

265 seasons (e.g. pest attacks, water quality and quantity, nutrient contents, moisture, temperature),

266 and on factors that contribute to crop yield variability. This data valuable for determining the

267 unique phenological cycles of agricultural crops in different geographic regions (Jensen 2000). .

268 A good example of this are date palms. Typically, date palm trees are 7-10 $\mathrm{m}$ tall with crowns $2-$

$2694 \mathrm{~m}$ in diameter, and the trees are normally spaced 3-5 $\mathrm{m}$ apart. The understory of date palm

270 plantations might include banana palms, mango trees, acacia bushes, vegetable crops, grain

271 crops, forage crops. The reflectance characteristics of a date palm area are often driven by the

272 density and health of the understory vegetation (Harris 2003). It can be difficult to use small

273 pixel data to study date palm areas with little or no understory vegetation because the small pixel 
274 effects may make it difficult to identify infestations (e.g. where date palms are infested between

275 mountains and dry rivers) given the tree spacing and density of leaves and branches. Studies like

276 (Hussain 1963; Mahmoudi et al. 2015) have revealed that heavy infestations occur mostly along

277 valleys. Additionally, the characteristics of the understory vegetation may dominate the

278 contribution of spectral responses rather than the tree vegetation themselves.

\subsection{Optical Remote Sensing Data}

281 The vital feature of RS is the detection of radiant energy emitted by various objects. The energy

282 detected might be in the form of acoustic energy (sound) or electromagnetic energy (visible light,

283 infrared heat, ultraviolet and microwaves). Remote sensing technology deployed from the

284 ground, air, or space-based platforms is capable of providing detailed spectral, spatial and 285 temporal information on vegetation health and is particularly useful for crop yield estimation 286 applications (Justice et al. 2002)

The temporal resolution of remote sensing data is important for commercial monitoring or management projects. The commercial Landsat and SPOT have revisit intervals of 16 and 26 days, respectively. The IKONOS revisit times range from 1 to 3 days. On the other hand, airborne (aircraft-mounted) sensors are more amenable to user defined re-visitation. The capacity of high temporal resolution RS technology has been exploited for monitoring seasonal vegetation variations, 
over wide areas is the estimation of net primary production and deciding time boundary

296

297

298

299

300

301

302

303

304

305

306

307

308

309

310

311

312

313

314

315

316

317

conditions for crop yield modelling. We believe temporal RS data can be used to study seasonal

DB infestations because there are two generations, namely spring and autumn.

Longer term temporal images (e.g. covering a 15-year period) can be used to classify and to determine the directions and speed of spread of DB infestations. . This approach can also be applied to historical images to obtain as much information as possible on selected areas. Change detection can also be performed to quantify the degree of variation in the infestation levels that is needed to occur before the change can be detected by satellite technology. This is important for the development of a management and surveillance strategy for DB.

\subsubsection{Spatial Resolution of Remote Sensing Data}

Spatial resolution is measured in terms of the smallest target on the ground. The number of available image-forming pixels in the sensor and its distance from the ground contribute to determining the pixel-size on the ground and the overall image footprint allowing low and high spatial resolution data on insect pests like DB (Kerr \& Ostrovsky 2003). Depending on the goals of a study, technology with an appropriate spatial resolution should be chosen. For example, certain Landsat data sets have spatial resolution of $30 \mathrm{~m}$ while certain SPOT data sets have spatial resolution of $20 \mathrm{~m}$ in each dimension. If it is a large scale study (e.g. large orchard), Landsat imagery at a $30 \mathrm{~m}$ resolution may be sufficient.

However, if the study is for small orchards surrounding the mountains where several types of plantations are present, high resolution data would be needed. High resolution imagery products are available, such as SPOT's panchromatic $10 \mathrm{~m}$ resolution data sets and Landsat's multispectral scanner $20 \mathrm{~m}$ resolution imagery. Furthermore, very high resolution imagery are 
318 available, including QuickBird's $2.15 \mathrm{~m}$ resolution images or the National Agricultural Imagery

319 Programme's (NAIP's) 1m resolution orthophotographs (Boryan et al. 2011).

320 More recently, high resolution satellite imagery from IKONOS, which consists of 4 m resolution

321 multispectral imagery, have become available; but the costs for obtaining such data remain a

322 significant impediment to their widespread use. These high resolution images can be used to

323 classify and map the spatial distribution and infestation levels of DB. Very high resolution data

324 collected with unmanned aerial vehicle (UAV)-based remote sensing technology can be used for

325 detecting and mapping of plant diseases and infestations such as those due to DB.

326

327

2.2.3 Spectral Resolution of Remote Sensing Data

328

329

330

331

332

333

334

335

336

337

338

339

340

Spectral resolution is typically defined as the number of bands of the electromagnetic spectrum that are sensed by the RS device. A very important aspect of spectral resolution is the width of the bands. Different band-widths have been employed extensively in multispectral imagery applications, and these data often cover an entire colour or colours such as, the red and blue bands of the spectrum. Multispectral systems commonly obtain data for 3-7 bands in a single observation such as in the visible and near-infrared regions of the electromagnetic spectrum. Multispectral imagery, however, lacks the sensitivity to detect subtle changes in tree canopy reflectance that are caused by physiologic stress from insects or pathogens (Lawrence \& Labus 2003).

Dakshinamurti et al. (1971) found that multispectral photography is useful for clearly differentiating between coconut plantations and other crops such as jack fruit, mangoes and bananas in India. Another relevant study Leckie et al. (2004) used multispectral data for detecting and assessing trees infested with Phellinus weirii which causes Laminated root rot 
341 disease . Other work (Stephens et al. 1971) has shown that multispectral photography can be

342 used to clearly distinguish between many types of fruit orchards and crops.

343 Hyperspectral imagery tends to have much narrower band widths, with several to many bands

344 within a single colour of the spectrum. These might include the visible (VIS), near-infrared

345 (NIR), mid-infrared (MIR) and thermal infrared portions. In the visible portion of the

346 electromagnetic spectrum (400 to $700 \mathrm{~nm}$ ), the reflectance of healthy green vegetation is

347 relatively low because of the strong absorption of light by the pigments in plant leaves. If there is

348 a reduction in pigments (e.g. chlorophyll) due to pests, the reflectance in the affected spectral

349 region will increase. A past study (Vigier et al. 2004) reported that reflectance in the red

350 wavelengths (e.g. 675-685 nm) dominated most of detection data for Sclerotinia spp. stem rot

351 infections in soybeans. Over approximately 700 to $1300 \mathrm{~nm}$ (the NIR portion), the reflectance of

352 healthy vegetation is very high. Damages caused by DB infestations in the form of black sooty

353 mould on palm tree leaves and understory vegetation that is promoted by bug excrement causes

354 overall reflectance in the NIR region to be lower than expected. The new hyperspectral RS

355 technology could be used to develop early (pre-visual) detection methods for DB infestations.

356

357 Colour-infrared technology with supporting hyperspectral reflectance data could be used to 358 identify specific trees and fronds of date palm trees that have been infested with DB. These 359 methods can be used to monitor changes in infestation levels according to honeydew, which is 360 converted to sooty mould on the fronds during high levels of infestation. Honeydew secretion is 361 a good indicator of DB feeding activity (Al-Abbasi 1988). The indirect assessments of the insect 362 populations can be carried out by measuring the amounts of honeydew caused by the insects 
363 (Southwood 1978). Additionally, Airborne Visible/Infrared Imaging Spectrometer (AVIRIS) can

364 be used to determine the extent and severity of DB infestation damage in different areas.

365

366

367

368

369

370

371

372

373

374

375

376

377

378

379

380

381

382

\subsection{Radar Data}

For many years, airborne technology has been employed in agricultural operations. Nevertheless, space-borne synthetic aperture radar (SAR) technology such as those of the Advanced Land Observing satellite; TerraSAR-X and Phased Array L-band have become available since the 2000s. Multiple radar sensors can work autonomously to detect solar radiation variation, but dissimilar optical sensors from which spectral reflectance measurements are taken affected differently by variation in the solar emission. Radar technology has found limited applications in regional studies because of its high costs, the narrow swath widths and limited extent of coverage.

The data can be extracted routinely by using the existing network of weather radars, and it can be used to alert growers that local crops are at heightened risk (Westbrook \& Isard 1999). Such information can then be used for fine tuning pest management practices such as pesticide applications, and could potentially reduce pesticide use by nearly $50 \%$ and lessen the overall impact of toxic chemicals on the environment (Dupont et al. 2000), as well as on the natural enemies of these insect pests. Table 2 shows example applications of different remote sensing technologies used to detect change in vegetation.

\section{Table 2. Example applications of the use of remote sensing technologies to detect} change in vegetation

\begin{tabular}{|l|l|l|}
\hline $\begin{array}{l}\text { Satellite } \\
\text { and aircraft } \\
\text { sensor }\end{array}$ & \multicolumn{1}{|c|}{ Spatial resolution } & Biophysical variables for vegetation \\
\hline
\end{tabular}




\begin{tabular}{|c|c|c|}
\hline $\begin{array}{l}\text { Landsat } 7 \\
(\mathrm{ETM}+)\end{array}$ & $\begin{array}{l}15 \mathrm{~m} \text { Panchromatic (Pan) bands; } 30 \mathrm{~m} \text { in the sex } \\
\text { VIS, NIR, IR and shortwave (SWIR) infrared } \\
\text { bands; and } 60 \mathrm{~m} \text { in the thermal infrared bands. }\end{array}$ & $\begin{array}{l}\text { Designed to monitor seasonal and small- } \\
\text { scale processes on a global scale such as } \\
\text { cycles of vegetation and agriculture. }\end{array}$ \\
\hline $\begin{array}{l}\text { Landsat } 8 \\
(\mathrm{OLI})\end{array}$ & $\begin{array}{l}15 \mathrm{~m} \text { pan bands; } 30 \mathrm{~m} \text { in the sex VIS, NIR, } \\
\text { SWIR1, SWIR2; and } 30 \mathrm{~m} \text { in the cirrus bands }\end{array}$ & \\
\hline ASTER & $\begin{array}{l}15 \mathrm{~m} \text { in the VIS and NIR range, } 30 \mathrm{~m} \text { in the } \\
\text { shortwave infrared band }\end{array}$ & $\begin{array}{l}\text { land cover classification and change } \\
\text { detection }\end{array}$ \\
\hline $\begin{array}{l}\text { NOAA } \\
(\text { AVHRR) }\end{array}$ & $1.1 \mathrm{~km}$ spatial resolution & $\begin{array}{l}\text { Large-area land cover and vegetation } \\
\text { mapping. }\end{array}$ \\
\hline SPOT & $\begin{array}{l}5 \text { and } 2.5 \text { meter in single-band, and } 10 \text { meters in } \\
\text { multiband. }\end{array}$ & Land cover and agricultural. \\
\hline $\begin{array}{l}\text { GeoEye } \\
\text { /IKONOS }\end{array}$ & $\begin{array}{l}\text { Panchromatic at } 1 \mathrm{~m} \text { resolution and multispectral } \\
\text { at } 4 \mathrm{~m} \text { resolution and color images at } 1 \mathrm{~m}\end{array}$ & $\begin{array}{l}\text { Pigments } \\
\text { Canopy structure }\end{array}$ \\
\hline $\begin{array}{l}\text { Digital } \\
\text { Globe's / } \\
\text { QuickBird }\end{array}$ & $\begin{array}{l}\text { Panchromatic with } 61 \text {-cenimetres resolution and } \\
\text { multispectral images with } 2.44 \mathrm{~m} \text { resolution and } \\
\text { color images with } 70 \text {-centimetres }\end{array}$ & $\begin{array}{l}\text { Biomass derive from vegetation indices } \\
\text { Leaf index }\end{array}$ \\
\hline $\begin{array}{l}\text { RADAR } \\
\text { (SAR) }\end{array}$ & $3 \mathrm{~m}$ resolution & Vegetation stress \\
\hline LIDAR & $\begin{array}{l}0.5 \text { to } 2 \mathrm{~m} \text { resolution and vertical accuracy of less } \\
\text { than } 15 \text { - centimetres }\end{array}$ & $\begin{array}{l}\text { Absorbed photosynthetically active } \\
\text { radiation } \\
\text { Evaporations }\end{array}$ \\
\hline
\end{tabular}

Fluorescence spectroscopy (FS) is a type of spectroscopic method by which fluorescence is measured of an object of interest following excitation by rays of light. Fluorescence has been used for vegetation research to monitor stress levels and physiological states in plants. There are two types of fluorescence. The first is blue-green fluorescence in the $\sim 400-600 \mathrm{~nm}$ range and the second type is chlorophyll fluorescence in the $\sim 650-800 \mathrm{~nm}$ range. Fluorescence spectroscopy can be used to monitor nutrient deficiencies, environmental conditions based on stress levels, infestations and plant diseases. In fact, it can be used to monitor fruit quality, photosynthetic 
392 activity, tissue stress and infestations in many types of crops (Karoui \& Blecker 2011; Tremblay

393 et al. 2012).

394 Remote Sensing is a powerful technique for visualising, diagnosing and quantifying plant 395 responses to stress like temperature, drought, salinity, flooding and mineral toxicity. Approaches

396 can range from the use of simple combinations of thermal and reflectance sensor data to visible 397 reflectance and fluorescence data. In particular, combined fluorescence reflectance and thermal 398 imaging sensor data can be used for quick investigations of vegetation stress (Lenk et al. 2007).

\subsection{Solar Radiation and the Humid-Thermal Ratio (HTRI-)}

400 Biological systems are highly dependent on two most important climatic factors, namely 401 temperature and precipitation. Temperature is influenced by solar radiation and thermal

402

403

404 405

406

407

408

409

410

411

412

413

emissions, while precipitation controls the dry or wet conditions (humidity) associated with plant growth. These factors are especially important in regions where extreme temperatures and humidity conditions are prevalent and large fluctuations exist throughout the seasons as such conditions can predispose plants to insect pests and diseases. In this regard, solar radiation models can be used to investigate insect infestations. Solar radiation models can be applied to calculate the potential solar radiation at a chosen location over a 12-month period.

The results from solar radiation studies can then be used to find correlations with different infestation levels to examine if solar radiation plays a determinant role in different infestation levels (see Figure 2). Solar radiation can also be used to study the presence/absence and density of animals, plants diseases and infestations such as those caused by DB. More information on the theory and technical aspects of solar radiation models can be found in (Bonan 1989; Dubayah \& 
414 Rich 1995; Flint \& Childs 1987; Geiger et al. 2002; Hetrick et al. 1993; Kumar et al. 1997; Swift 415 1976).

416

417

418

419

420

421

422

423

424

425

426

427 428

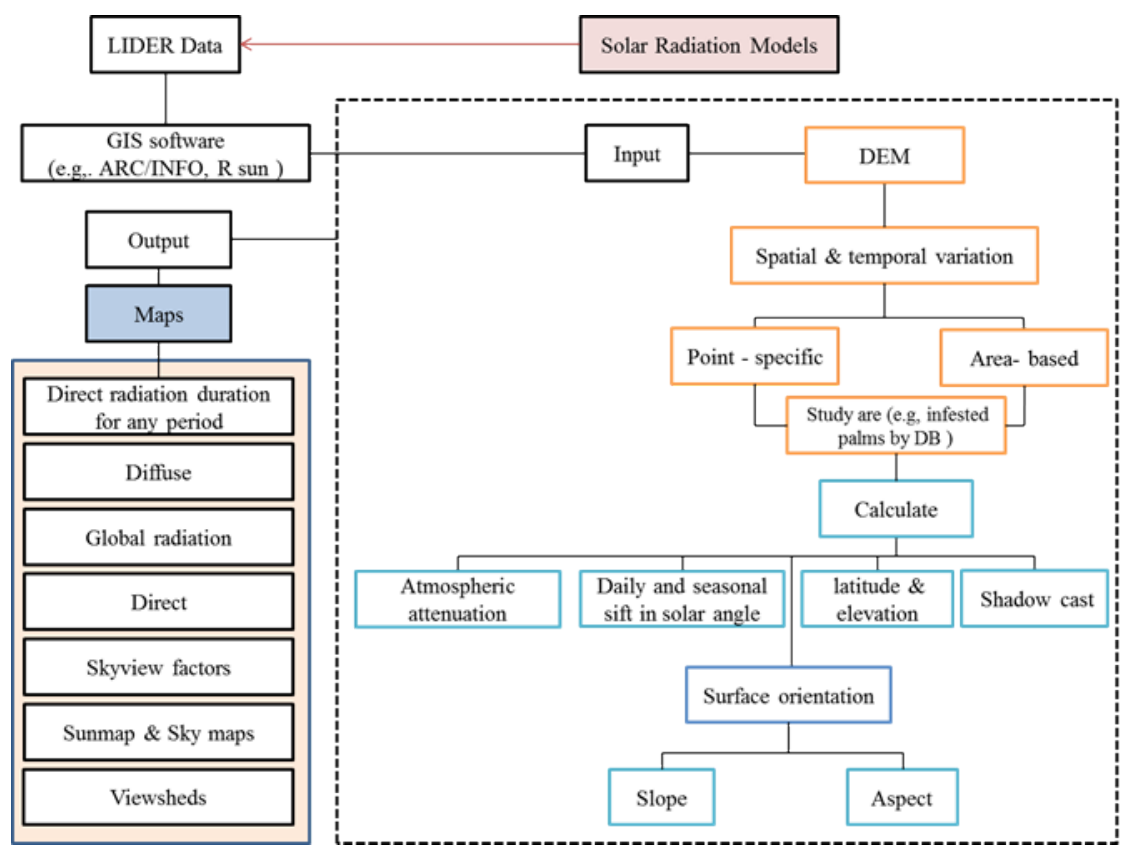

Figure 2. A diagram showing the design and use of solar radiation models to analyse the relationship between Dubas bug infestation levels and positional solar radiation

The Humid-Thermal Ratio (HTR), has successfully been used to develop and test relationships between different plant infestations levels in varied climate conditions in areas such as Australia, India, Europe, and North America. An HTR prototype has been developed to simulate ecological conditions appropriate for the establishments and spread of plant diseases in India (Jhorar et al. 1997). The HTR method has also been used to evaluate the risk of the establishment and spread of Karnal in wheat, grown under a variety of climatic conditions and in different areas (Mavi et al. 1992; Stansbury \& Pretorius 2001; Workneh et al. 2008). This method has potential value in researching insect pests and their associated diseases, which may allow for the predictions of occurrence and non-occurrence under specific combinations of climate and weather conditions. 


\section{3. Vegetation}

\subsection{Image processing for vegetation}

431 In order to detect changes, important information must be provided including spatial

432 distributions of change, change rates, change trajectories for different vegetation types, and 433 assessment of the accuracy of the change detection results. The three main steps in implementing 434 change detection are (1) image pre-processing, e.g geometrical rectification (GR), image 435 registration (IR), minimum noise fraction (MNF) analysis, radiometric, automorphic and 436 topographic correction (the latter is needed if the study area is close to mountains) (Bagheri et al. 437 2016; Bishop \& Colby 2002; Civco 1989; Teillet et al. 1982); (2) selection of optimal techniques 438 to conduct the change detection analysis; and (3) accuracy assessments (Datt et al. 2003; Lu et al. 439 2004; Lunetta et al. 2006; Lyon et al. 1998; Song et al. 2001) (see Figure 3).

440 Although the selection of appropriate change detection techniques is important for the accuracy 441 of change results; in practice, it might not be easy to select a suitable algorithm for a specific 442 change detection application. Some simple techniques can be used to provide change and non-

443 change information (e.g. image differencing). Other techniques may be used to provide a 444 complex matrix of change direction data such as that used for post-classification comparisons 445 (Lu et al. 2004). This review provides examples of change detection methods that can be used to 446 address DB infestations and their impacts on date palm trees.

\section{3.2 Techniques and Methods}

\subsubsection{Vegetation Indices}

449 Vegetation indexes (VIs) are used to compile data into a single number that quantifies vegetation 450 biomass and/or plant vigour for each pixel in a RS image. An index is computed by using several 
451 spectral bands that are sensitive to plant biomass and vigour. Such indices can be used to (1)

452 specify the amount of vegetation (e.g. biomass, SAVI, the percentage of vegetation cover); (2)

453 discriminate between soil and vegetation; and (3) reduce atmospheric and topographic effects.

454 However, variability in VI data can arise from atmospheric effects, viewing and illumination

455 angles, sensor calibrations, errors in geometric registration, subpixel water and clouds, snow

456 cover, background materials, image compositing and landscape topography (e.g. slope and

457 relief). For example, in sparsely vegetated areas, the reflectance of soil and sand are much higher

458 than the reflection of vegetation; so the detection of reflection from the vegetation cover is 459 difficult.

\subsubsection{Difference Vegetation Index}

461 The Difference Vegetation Index (DVI) is the simplest vegetation index (DVI = NIR - Red).

462 DVI is sensitive to the amount of vegetation, and it can be used to distinguish between soil and

463 vegetation. However, it does consider the difference between reflectance and radiance caused by

464 the atmosphere and shadows (Jiang et al. 2006). Previous research (Glenn et al. 2008) that used

465 the utility of image differencing, image rationing, and the vegetation index for detecting gypsy

466 moth defoliation found that a difference of the MSS7/MSS5 ratio was more useful for 467 delineating defoliated areas than any single band-pair difference.

\section{3.2.1.2 Ratio-Based Vegetation Indices}

469 Ratio-based Vegetation Indices are also called the simple ratio (SR) or RVI (SR = NIR/Red).

470 The SR provides valuable information about vegetation biomass or Leaf Area Index (LAI)

471 variations in high-biomass vegetation areas such as forests. It is also useful in low-biomass

472 situations, such as those containing soil, water, ice, etc., where the SR indicates the amount of 
473 vegetation present. The SR is capable of reducing the effects of the atmosphere and topography

474 on the analysis results.

475 3.2.1.3. Normalised Difference Vegetation Index

476 Normalised Difference Vegetation Index (NDVI) are generally well-documented, quality-

477 controlled data sources that have been re-processed for many applications and problems. It is

478 possible to use the NDVI values to discriminate between dense forests, non-forested areas,

479 agricultural fields and savannahs; however, distinguishing between forests with different

480 dominant species is not possible by using this type of RS data because several assemblages of

481 plant species can produce similar NDVI values or similar NDVI temporal trends. Atmospheric

482 conditions are another aspect that must be considered when using the NDVI.

483 One study Nageswara Rao et al. (2004) reported that bananas and coconuts have close greenness

484 profiles in mid-April, but have rather distinct greenness profiles in mid-March. Another study

485 Chavez \& MacKinnon (1994) reported that red band image differencing provided better change

486 detection results for vegetation than red data when using the NDVI in arid and semi-arid

487 environments of south-western United States. The NDVI may not be appropriate to use in dry

488 areas, and caution is warranted for such applications. Date palms trees are often planted in a

489 regular grid pattern, as are olive trees and such trees may be able to be easily distinguished with

490 NDVI data.

491 3.2.1.4. Normalisation Difference Moisture Index

492 The Normalisation Difference Moisture Index (NDMI) data can be used to determine the

493 threshold presence of pest infestations (green attack). Such data can also be potentially used for

494 deriving regional estimates of the year of stand death, for example, by using Landsat data and 
495 decision tree analysis. However, there are limitations associated with using the NDMI, which

496 include difficulties in detecting low rates of infestation and the need to add images from other

497 dates (to achieve a higher temporal frequency) to quantify the spectral response to insects such as

498 the DB.

499 The application of a VI such as the NDVI and SAVI to multispectral satellite imagery (blue, red 500 and NIR) has been shown to be useful to quantify variations in plant vigour, make relative 501 biomass predictions, assess yields and investigate the occurrences of pests and disease attacks 502 outbreaks (Plant 2001). Landsat TM data can be used to assess both plant age and LAI values by 503 applying a number of indices such as the Shadow Index (SI), Bare soil Index (BI), NDVI, and 504 Advanced Vegetation Index (AVI).

505

506

507

508

509

510

511

512

513

514 spectral information.

515 The PCA and the KTC transformations can be used for land cover change detection via NIR

516 reflectance or greenness data that can detect crop type changes between vegetation and non-

517 vegetation features (Gorczyca et al. 1993; Lu et al. 2004). An earlier study (Rondeaux et al. 
518 1996) found that SAVI, where the value $X$ was tuned to 0.16 , easily out-performed all other

519 indices when applied to agricultural surfaces. Others (Kaufman \& Tanre 1992; Leprieur et al.

520 1996) have concluded that the GEMI and ARVI are less sensitive to atmosphere, but may be

521 incapable of dealing with variation in soil reflectance. More information about feature space

522 transformation can be found in (Gebauer et al. 2007; Luedeling \& Buerkert 2008). According to

523 (Darvishzadeh et al. 2008), REP is the most studied feature on vegetation spectral curve because

524 it is strongly correlated with foliar chlorophyll content and can be a sensitive indicator of stress

525 in vegetation.

\section{3.2.3. Classification}

527 The objective of image classification is to categorise all pixels in the imagery into one of several

528 land cover classes or themes. The categorised data can then be used to produce thematic maps of 529 land cover (e.g. vegetation type) based on remotely sensed data. Most image processing 530 techniques offers several methods to test hypotheses. The best-known methods include 531 supervised and unsupervised classification; however, these techniques require ground reference 532 data.

533 Maximum Likelihood Classification, for example, requires samples of pixels obtained by field 534 observations or aerial photography interpretations that are deemed to be representative of 535 specific land cover types. The Maximum Likelihood method relies on the assumption that the 536 populations from which these training samples are drawn, are multivariate-normal in their 537 distributions. The traditional methods employ classical image classification algorithms (e.g. $k$ 538 means and ISODATA) for unsupervised classification, and maximum likelihood classification 539 for supervised classification. 
540 3.2.3.1. Maximum likelihood classification algorithm

541 The maximum likelihood classification algorithm (or parametric information extraction) is the

542 most widely adopted parametric classification algorithm. However, it requires normally

543 distributed training data, especially for $n$ (rarely the case) to compute the class variance and

544 covariance matrices. Another limitation is that it is difficult to integrate non-image categorical

545 data into a maximum likelihood classification. However, fuzzy maximum likelihood

546 classification algorithms are also available (Zhang \& Foody 2001).

547 3.2.3.2. Classification techniques

548 Supervised classification. The supervised classification methods can be used to select 549 representative samples for each land cover class in a digital image. Sample land classes are more 550 commonly called training sites. The image classification software uses the training sites to 551 identify the land cover classes in the entire image. The classification of land cover is based on 552 spectral signatures defined in the training set. The digital image classification software

553 determines the class based on what it resembles most in the training set. The limitation on the use 554 of supervised classification is that analysis are required to identify areas on an image of known 555 informational types and to create a training area (group of pixels) from which the computer 556 generates a statistics file (Mountrakis et al. 2011).

557 Unsupervised classification. The advantage of the use of unsupervised classification is that all 558 spectral variation in the image are captured and used to group the imagery data into clusters. The 559 major disadvantage is that is difficult to completely label all the clusters to produce the thematic 560 map.

561 Combined and advanced methods. Many examples exist whereby the supervised and 562 unsupervised techniques were combined together in analyses. The associated advantages and 
563 disadvantages can be found in (Castellana et al. 2007; Pao \& Sobajic 1992). However, the

564 combined approach only slightly improves the ability to create thematic maps when compared to

565 using each technique separately. Moreover, a large amount of effort has been devoted to

566 developing advanced classification approaches to improve our ability to create thematic maps

567 from digital remotely sensed imagery. One of the most recent advances has been the adoption of

568 artificial neural networks (ANNs) in the place of maximum likelihood classification (standard in

569 most RS software). This review only covers a few of the non-parametric techniques.

570

571 Artificial neural network (ANNS). Fortunately, the ANN methods (non-parametric information

572 extraction) do not require normally distributed training data, and may be used to integrate with

573 virtually any type of spatially distributed data in classification. The disadvantage of using ANN

574 is that occasionally it is difficult to determine exactly how the ANN came up with a certain

575 assumption because such information is locked within weights in a hidden layer or layers. The

576 method has been used successfully for classifying infestations, diseases/conditions of plants and

577 the associated damage based on spectral data (Cox 2002; Liu et al. 2010; Pydipati et al. 2005). In

578 recent years, spectral mixture analysis, ANNs, GISs and RS data have become important tools

579 for change detection applications.

580 Artificial intelligence (AI). Use of nonmetric information extraction or AI methods allows the 581 computer to analyse data perhaps better than people. The benefits of using AI for image analysis

582 involve the use of expert systems that place all the information contained within an image in its 583 proper context with ancillary data and then to extract valuable information (Duda et al. 2001).

584 Classification and regression tree (CART). Classification and regression tree is a non-parametric 585 algorithm that uses a set of training data to develop a hierarchical decision tree. The decision tree 
586 is created by using a binary partitioning algorithm that selects the best variable by which to split

587 the data into separate categories at each level of the hierarchy. Once the final tree is generated, it 588 can be used to label all unknown pixels in the image. This method is extremely robust and 589 provides significantly better map accuracies than those that have been achieved by using more 590 basic approaches (Lawrence \& Wright 2001).

591 Support vector machines (SVMS). Support vector machines are derived from the field of 592 statistical learning theory and have been used in the machine vision field for the last 10 years. 593 These methods have been developed for use in creating thematic maps from remotely sensed 594 imagery. The SVM performs by projecting the training data using a kernel function and this 595 results in a data set that can then be linearly separated. The capability to separate out the various 596 informational classes in the imagery is a powerful advantage. The use of SVM is relatively new, 597 but it offers great potential for creating thematic maps from digital imagery.

598 Several advanced techniques for classifying digital remotely sensed data involve the extensive 599 development and adoption of object-based image analysis. Moreover, advanced image 600 classification techniques such as $k$-means, ISODATA, fuzzy ARTMP, fuzzy multivariate cluster 601 analysis, the WARD minimum variance technique, SOM, the artificial neural classification 602 algorithm (i.e. for the propagation of neural networks and self-organising maps) and Bayesian 603 analysis can be used (1) for the classification of remotely sensed data; and (2) to delineate 604 horticultural crops in satellite maps. The major advantage of these techniques is their ability to 605 generate a matrix of change information and to reduce external impacts from the atmospheric 606 and environmental differences among the multi-temporal images. However, it may be difficult to 607 select high quality and sufficiently numerous training sets for image classification, in particular 
608 for important historical image data classifications due to the lack of data (Lu et al. 2003; Lu \&

609 Weng 2007; Lunetta et al. 2006; Monteiro et al. 2003; Rogan et al. 2002).

610 All these classifications are performed on a pixel-by-pixel basis. Therefore, given that a pixel

611 maps an arbitrary delineation of an area on the ground, any selected pixel may or may not be

612 representative of the vegetation/land cover of that area. In object-based image analysis (OBIA),

613 unlabelled pixels are grouped into meaningful polygons that are then classified as polygon pixels

614 (Blaschke 2010; Dey et al. 2010; Haralick \& Shapiro 1985; Stafford 2000) .

615 Classified satellite imagery can also be used to extract palm crown data. The centre of crowns

616 can be isolated because they often remain green and are not as severely impacted by the DB as

617 the palm fronds. Densities of the DB tend to be highest outside of the crown region. The removal

618 of the centre and concentration on the outer parts of the vegetation can then lead to a higher

619 probability of detecting the impacts of DB and categorising the infestation levels accurately. The

620 images can also be used by classification techniques (e.g. unsupervised) to detect stages for

621 which users do not have ground truth data.

622 3.2.4 Image Segmentation Techniques

623 Image segmentation techniques can be used to extract information on palm canopies. The crown 624 information can be used to calculate the density of palms per unit. This information can then be 625 applied as part of a GIS-based spatial analysis to answer questions about whether infestation 626 levels are linked to the density of palms or not. The crown information could also be used to 627 determine the random or systematic nature of farms.

628 This information can be further used in GIS-based analyses to answer questions about whether or 629 not randomly situated plants have a higher risk of infestation than non-randomly situated plants.

630 Such information would be useful for determining the optimal row spacing. Research published 
631 in the literature suggests that those plantations that have wide row spacing have a lesser

632 likelihood of DB infestations (Ali \& Hama 2016). The row spacing data extracted from satellite

633 imagery could thus be used to confirm the relationship between row spacing and infestation

634 levels.

635 3.2.5. Image Fusion

636 Image fusion is a technology that merges two or more images of the same area collected by

637 different sensors or at different wavelengths. For example, merging a $2.5 \mathrm{~m}$ multispectral image

638 with a $0.7 \mathrm{~m}$ panchromatic image can be done to capitalise on the advantages of both image sets.

639 The panchromatic images have very good spatial resolution but lack the multiband information

640 that the $2.3 \mathrm{~m}$ multispectral image provides. Thus, the advantage of using image fusion for

641 change detection is that fusion can allow for both high spatial and spectral resolutions, which

642 will enable users to extract high quality land cover/vegetation information (Boryan et al. 2011;

643 Simone et al. 2002). Image fusion techniques such as the HSV (hue, saturation, value), Brovey,

644 Gram-Schmidt and Principle Components methods can be used to compare the accuracy and

645 distortion levels of images (e.g., 8-band Worldview images).

646 4. Accuracy Assessment

647 Accuracy assessment is an important part of any classification algorithm process, and it should

648 be undertaken for every project because it is difficult to know how accurate a classification is

649 without an accuracy assessment. The accuracy of a classification is usually assessed by

650 comparing the classification with some reference data that is believed to accurately reflect the

651 true land-cover. Reference data may include ground truth data, higher resolution satellite images

652 and maps derived from aerial photographic interpretations. However, in the case for all reference 
653 data, even ground truth data, these data sets may also contain some inaccuracies. More

654 information about accuracy assessments can be found in (Al-Kindi et al. 2017b; Congalton 2001;

655 Foody 2002; Gibbs et al. 2010; Hirano et al. 2003; Huang et al. 2007; Hughes et al. 2006).

656

657 Positional accuracy methods can be used to provide an assessment of the differences in distance 658 among a sample of locations on the map and those same locations on a reference data set. This 659 same basic process can be used in assessing the thematic accuracy of a map, and it involves a 660 number of initial considerations such as taking into account the sources of errors and the proper 661 selection of classification systems. Determination of the thematic accuracy is more complicated 662 than that of the positional accuracy.

663 This is due to the size requirements for sampling thematic accuracy assessments, which are 664 larger than those for positional accuracy assessments. An error matrix technique can be used to 665 compute the thematic accuracy, and the error matrix can be generated by using reference data 666 and correct or incorrect designations; one can also use qualifiers such as good, acceptable and 667 poor to produce a fuzzy error matrix. Additionally, there are a number of analysis techniques that 668 can be performed using the error matrix, such as the Kappa analysis. The Kappa analysis can be 669 used to test statistically whether or not one error matrix is significantly different than another 670 (Goodchild 1994). 


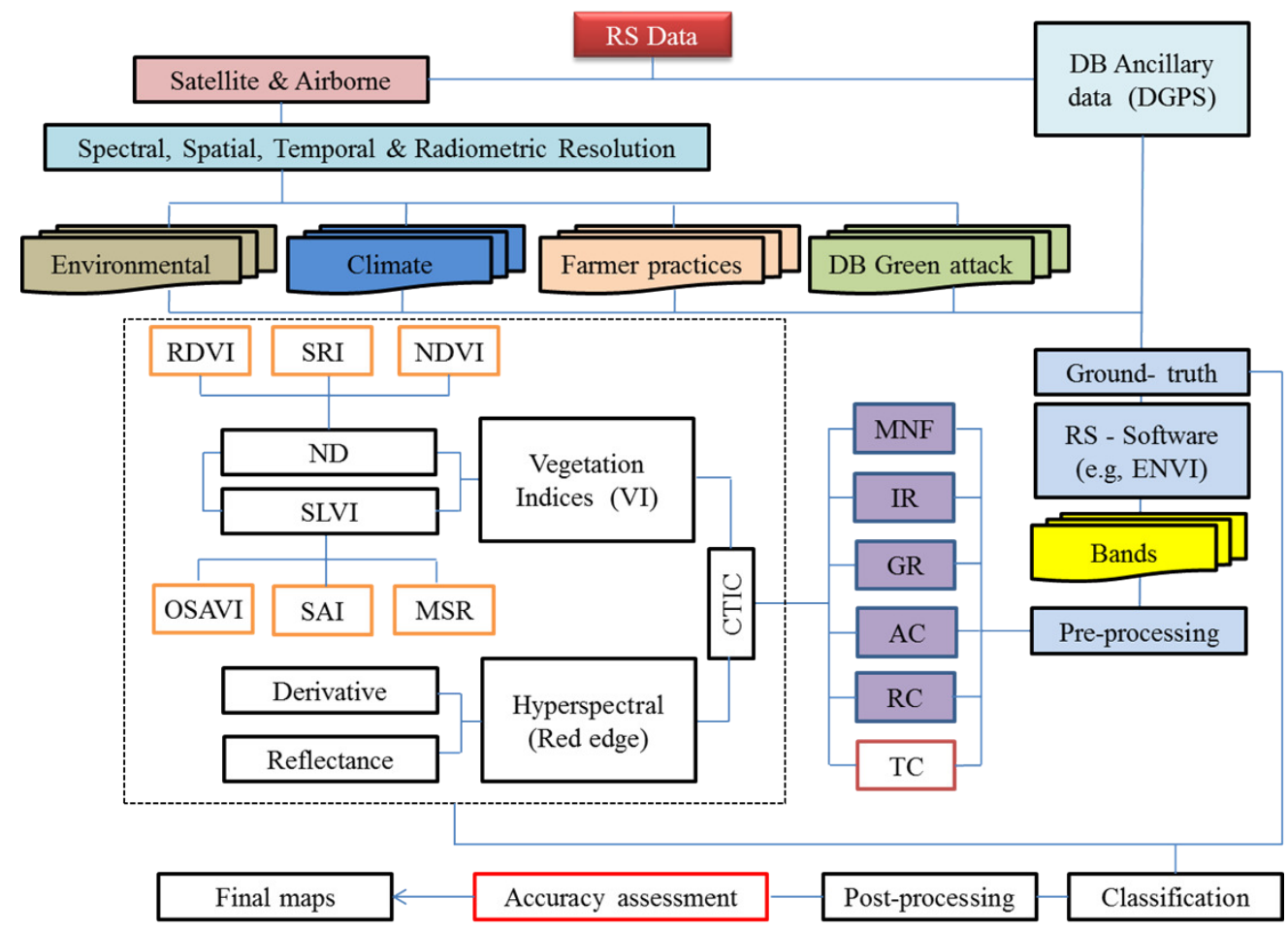

673 Figure 3. Flowchart of an image processing methodology, which include three main steps

674 for implementing change detection research, namely (1) image pre-processing work;

675 geometrical replication (GR), image registration (IR), minimum nose fraction (MNF)

676 analysis, radiometric correction (RC), atmospheric correction (AC) and topographic

677 correction (TC); (2) selection of optimal techniques to conduct the change detection; and (3)

678 accuracy assessments to obtain final maps.

\section{Modelling the spatial relationships between insect infestations and the environmental}

\section{and climate factors}

681 While RS techniques focus on visual and pre-visual detection and mapping, spatial analytical

682 techniques can be used to evaluate correlations, identify important variables, and develop 683 predictive models. Spatial statistics functions and tools have made it possible to implement state-

684 of-the-art spatial autoregressive techniques to investigate many research problems (e.g insect pest) (Carrière et al. 2006; Carruthers 2003) . Advances in spatial analytical techniques software, 
686 such as ArcInfo ${ }^{\circledR}$, have greatly reduced the time for estimating spatial parameters. For example, 687 regression analysis allows users to examine, model and explore spatial relationships in order to 688 better understand the factors behind the observed spatial patterns. It also allows users to predict 689 hypotheses based on understanding of these factors. There are three main types of regressions, 690 namely, linear regression, local regression, and logistic regression (Liebhold et al. 1993; 691 Wichmann \& Ravn 2001). Linear regression can be used to predict the values of $y$ from values of $692 x_{i}$ as follows:

$$
y=a+b_{1} x_{1}+b_{2} x_{2}+\ldots+b_{n} x_{n}
$$

694

695

696

697

698

699

700

701

702

703

704

705

706

707

where $y$ is the dependent variable, $x_{i}$ represents the independent variables $i$, and $b_{i}, \ldots, b n$ are the regression coefficients. However, this requires several assumptions about the error, or residuals, between the predicted values and the actual values (Miles \& Shevlin 2001). Some errors are related to a normal distribution for a set of independent variables, while others are related to the expected mean value of zero. Linear regression has been used to model wildlife home ranges (Anderson et al. 2005) and soil moisture (Lookingbill \& Urban 2004). According to Harris et al. (2010), Local Regression or Geographically Weighted Regression (GWR) analysis can be used to predict information for every known point in order to derive a local model. Moreover, parameters for this method can include variations in space, thereby providing a basis for exploring non-stationary spatial relationships. The logistic regression method can be applied to model spatial relationships between features, such as when the dependent variable is categorical (e.g., presence or absence data) and when the independent variables are categorical, numeric or both (Menard 2002). The advantage of using the logistic regression is that it does not require the same set of rigid assumptions as required by linear regression. 
708 Various studies have involved the use of autoregressive models to investigate the relationships

709 between insect infestations and factors that are based on environmental information. Munar-

710 Vivas et al. (2010) combined environmental information, spatial data and attribute data in GIS-

711 based maps to assess the impact of Moko disease on banana yields in Colombia. Specifically,

712 they used a regression model to investigate the relationship between infested areas and distances

713 from the Moko foci to cable-ways and drainage channels. Coops et al. (2006) studied the

714 associations among the likelihood of occurrence, forest structure and forest predisposition

715 variables using regression tree models. They found through modelling that location and slope

716 were the major factors driving variations in the probability of red tree outbreaks. The GWR

717 model has been used to detect high-risk infestations caused by mountain pine beetle invasions of

718 lodge-pole pine forests over large areas (Robertson et al. 2008).

719 It is important to start by using single variables to develop correlations before moving to more

720 complicated predictive models and regression analyses, where all factors are incorporated to

721 investigate which combination of factors is most conducive to the survival and spread of insects

722 or diseases. In our study, for instance, GWR could be used to model the correlation between DB

723 infestation and meteorological variables such as humidity, rainfall, temperature, wind direction

724 and wind speed; GWR could also be applied to model the correlations between DB infestations

725 and environmental variables including soil type, slope, aspect ratio, ecology, soil salinity and

726 solar radiation. Additionally, autoregressive models could be used to investigate the relationships

727 between DB infestations and human practices such as irrigation, plantation systems, insecticide

728 use, and methods of spraying (Al-Kindi et al. 2017a). 
730 All of the methods used to study the relationships between dependent and independent variables

731 discussed previously are traditional statistical methods, which sometimes might not reflect the

732 complicated relationships between infestations and environmental factors. In particular,

733 ecological and geographical environments represent complex systems in which individual

734 elements interact to create complex behaviour, and consequently, complex methods such as

735 ANN, Cellular Automata (CA), and multi-agent systems (MAS) may be better suited to study the

736 relationships and conduct factor analyses in insect infestation or disease detection research and to

737 perform spread simulations (De Smith et al. 2007).

738 Numerous suitability models have been proposed to identify locations that have a particular set 739 of characteristics.

740 In (Hernandez et al. 2006), the authors compared four different models (BIOCLIM, GAPP,

741 DOMIN and MAXENT) and found that MAXENT was most capable for producing useful

742 results with small sample sizes and minimum species occurrences. These models can also be

743 used to identify areas that are susceptible to risks such as insect infestations, based on conditions

744 favoured by the species. For example, a relevant study (Drees et al. 2010) used the habitat

745 suitability selection method to model potential conservation areas for a rare ground beetle

746 species (using Barcode Index Number or BIN). Specifically, they used five different data sets to

747 identify several key habitat factors for Carabus variolosus stress levels. A model was developed

748 in (Bone et al. 2005) by using fuzzy theory to identify areas of susceptibility to Dendroctonus

749 ponderosae Hopkins in Canada. However, Spatial data have unique characteristics that can

750 impact the results of the model (Crooks \& Castle 2012).

751 Raster data models are often used for finding and rating suitable locations. The raster overlay

752 results are formatted in a single layer of suitable versus unsuitable cells, rather than in a vector 
753 layer with many polygons and an attribute table, which contains the attribute values for each of

754 the polygons. There are two ways to create raster suitability layers. The first approach is to query

755 the individual sources to create the suitability layer. The query can be used to create a suitability

756 layer with two values, ' 1 ' for cells meeting all criteria of a suitable habitat, and ' 0 ' for the others.

757 Because the layer consists of only two values, one indicating suitable and the other unsuitable

758 cells, they are called binary suitability layers. Binary processing however is not always

759 necessary. Combined with other evaluation models, suitability mapping can be achieved by

760 overlaying directly or by post processing the overlay results. Figure 4 shows a process that could

761 be used to find suitable location conditions (habitat) for insects such as DB by using a raster

762 method overlay.

763

764

765

766

767

768

769

770

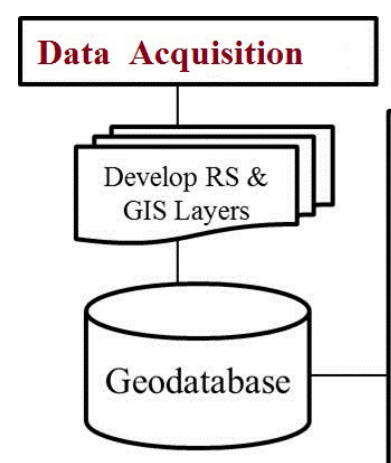

Figure 4. Schematic of the process that can be used to model the suitable location for

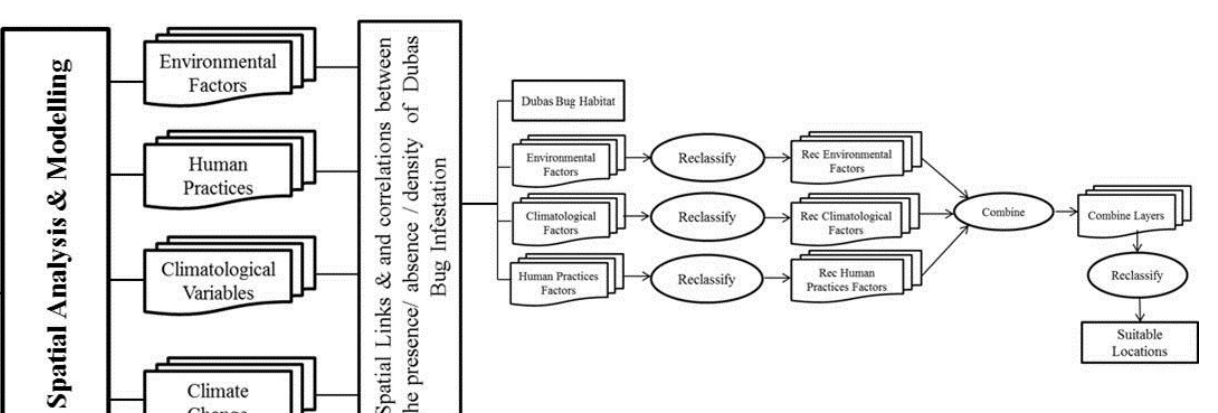

The uncertainty that results from geo-processing operations, demonstrates that sophisticated spatial analysis cannot be achieved using traditional, deterministic geoprocessing methods alone (Goodchild \& Glennon 2010; Zhang \& Goodchild 2002). Fuzzy logic is a superset of Boolean logic and has the ability to handle uncertainty in data that arises from vagueness instead of randomness alone ( $\mathrm{Li}$ et al. 2010). 
771 Fuzzy logic can be utilised to extract information from high resolution RS data and combined

772 with a raster-based spatial data to produce maps representing the spatial variation of vulnerability

773 to pests across a landscape (Zhang \& Foody 2001). This method also allows for partial

774 association with one or more classes, meaning that objects may be represented by a value based

775 on a membership function between ' 0 ' and ' 1 '( $\mathrm{Li} \&$ Zhao 2007). The membership function of an

776 element $x$ belonging to a fuzzy set $\mathrm{A}$ is computed by:

777

778

$$
\mu_{A}: U \rightarrow[0,1]
$$

779

780

781

782

783

784

785

786

787

788

789

790

791

where $U$ is the universal set of $x$. The concept of fuzzy sets has also been employed for defining the spatial and attributes characteristics of geographic objects (Burrough \& Frank 1996; Wang \& Hall 1996). The results of such analysis can be rendered directly into a decision framework via maps, tables, and charts. The results can also be used in further analyses or to provide additional understanding of the problem.

The challenge in any particular area of study is the geographical extent and the resolution of analysis, which is determined by the phenomenon being modelled. To achieve validity, researchers must ensure that they are using accurate and current data whenever possible. If the data are from one's own organisation, one can rely on data quality controls that are in place. Data quality should be checked against alternate sources if possible in order to ensure it meets the requirements of the analysis. Assessing the quality of data will provide guidance to predicting what level of confidence can be attributed to the result of the modelling work.

\section{Proof-of-concept Cases}


792 The first proof-of-concept case is published in (Al-Kindi et al. 2017a). In this paper, we analysed

793 a set of IKONOS satellite images collected in 2015 on our study area (5 meters spatial

794 resolution) by processing them using chosen image segmentation functions and extracted density

795 information of the palm canopies. The techniques used can be found in Section 3.2.4.

796 Next, sample locations (i.e. GPS points) were identified in the satellite images by examining

797 their Normalised Different Vegetation Index (NDVI) values. NDVI served as a surrogate

798 measure of palm plantation density and homogeneity in the neighbourhood surrounding an image

799 pixel. The relevant techniques can be found in section 3.2.1.3.

800 In addition, spatial statistical techniques including Geographically Weighted Regression,

801 Ordinary Least Squares and Exploratory Regression (corresponding implementations included in

802 ArcGIS ${ }^{\mathrm{TM}}$ ) were applied to study the correlations between various human factors related to date

803 palm farming and the distribution density of the DB. These techniques have been reviewed in

804 Section 5.

805 The second proof-of-concept case is published in (Al-Kindi et al. 2017b). In that paper, we

806 applied spatial statistical techniques to model spatiotemporal patterns of DB on date palm in

807 north of Oman. Data on the DB infestations and their impact were collected through observations

808 of palm trees from 2006 to 2015 by the Ministry of Agriculture and Fisheries of the Sultanate of

809 Oman. The techniques used can be found in Section 5 and Section 2.1.

\section{7. Conclusions}

811 In this review, a variety of spatial information technologies, including remote sensing and spatial

812 statistical methods, have been shown to be useful in areas of research involving insect

813 infestations worldwide. Environmental and climatic conditions are very important in determining 
814 the distribution and survival of any species, including the DB, which is a problematic pest in date

815 palm plantations. We argue that most of the current research on DB has focused on its ecology,

816 biology or control mechanisms only. There has been very limited research linking the

817 presence/absence, density, spatial and temporal distributions of DB with environmental,

818 meteorological, and human practices that promote its development, prevalence and spread.

819 Understanding the distribution and affinity of the Dubas bug in terms of these variables and 820 mapping of the data can play a key role in its control and management, as well as resource 821 allocation.

822

823

824

Acknowledgments: We thank the Unit of Cultivations Protection in the Ministry of Agriculture 825 and Fisheries of the Sultanate of Oman for providing the data on DB infestations in the study 826 area.

827

828

829

830

831

832

833

834

835

836

837

838

839

840

841

\section{References}

Abdullah A, and Umer M. 2004. Applications of remote sensing in pest scouting: evaluating options and exploring possibilities. National University of Computers and Emerging Sciences, Pakistan:p.1-13.

Abdullah SK, Lorca L, and Jansson H. 2010. Diseases of date palms (Phoenix dactylifera L.). Basrah J for Date Palm Res 9:1-40.

Acharya M, and Thapa R. 2015. REMOTE SENSING AND ITS APPLICATION IN AGRICULTURAL PEST MANAGEMENT. "Seven Billion Dreams One Planet Consume With Care.

Al-Abbasi S. 1988. Antennal sense organs of Ommatissus binotatus de Berg (Tropiduchidae: Homoptera). Date Palm Journal (FAO/NENADATES) eng (1988) v $6(2,=$ no 12) p 426-432.

Al-Azawi A. 1986. A survey of insect pests of date palms in Qatar. Date Palm Journal 4:247-266.

Al-Khatri S. Date palm pests and their control. J. E. Peña (Ed.), Proceedings of date palm regional workshop on ecosystem-based IPM for date palm in gulf Countries ,28-30 Mar 2004. Al-Ain. pp. 84-88.

Al-Khatri S. 2004. Date palm pests and their control. Proceedings, Date Palm Regional Workshop on Ecosystem-Based IPM for Date Palm in Gulf Countries UAE University, Al Ain, UAE. p 84-88. 
842

843

844

845

846

847

848

849

850

851

852

853

854

855

856

857

858

859

860

861

862

863

864

865

866

867

868

869

870

871

872

873

874

875

876

877

878

879

Al-Khatri SAH. 2011. Biological, ecological and phylogenic studies of Pseudoligosita babylonica viggiani, a native egg parasitoid of Dubas bug Ommatissus lybicus de Bergevin, the major pest of date palm in the Sultanate of Oman. University of Reading.

Al-Kindi KM, Kwan P, Andrew NR, and Welch M. 2017a. Impacts of human-related practices on Ommatissus lybicus infestations of date palm in Oman. PloS one 12:e0171103.

Al-Kindi KM, Kwan P, Andrew NR, and Welch M. 2017b. Modelling spatiotemporal patterns of dubas bug infestations on date palms in northern Oman: A geographical information system case study. Crop protection 93:113-121.

Al-Mahmooli H, Deadman M, and Al-Wahabi A. 2005. Evaluation of azadirachtin formulation for the control of dubas bug in Oman. Proceedings of the BCPC international congress of crop science and technology. p 551-556.

Al-Samarrie Al, and Akela AA. 2011. Distribution of injected pesticides in data palm trees. Agric Biol JN Am 12:1416-1426.

Al-Yahyai R. 2006. Improvement of date palm production in the Sultanate of Oman. III International Date Palm Conference 736. p 337-343.

Al-Yahyai R, and Al-Khanjari S. 2008. Biodiversity of date palm in the Sultanate of Oman. African Journal of Agricultural Research 3:389-395.

Al-Yahyai R, and Khan MM. 2015. Date Palm Status and Perspective in Oman. Date Palm Genetic Resources and Utilization: Springer, 207-240.

Al-Zadjali TS, Abd-Allah F, and El-Haidari H. 2006. Insect pests attacking date palms and dates in Sultanate of Oman. Egyptian Journal of Agricultural Research 84:51-59.

Aldryhim Y. 2004. Dubas Bug (Old World Date Bug), Ommatissus Lybicus Bergerin (Tropiduchidae: Hemiptera). Encyclopedia of Entomology: Springer, 727-727.

Ali A-SA, and Hama NN. 2016. Integrated management for major date palm pests in Iraq. Emirates Journal of Food and Agriculture 28:24-33.

Aminaee MM, Zare R, and Assari MJ. 2010. Isolation and selection of virulent isolates of Beauveria bassiana for biological control of Ommatissus lybicus in Kerman province. Archives of phytopathology and plant protection 43:761-768.

Anderson DP, Forester JD, Turner MG, Frair JL, Merrill EH, Fortin D, Mao JS, and Boyce MS. 2005. Factors influencing female home range sizes in elk (Cervus elaphus) in North American landscapes. Landscape Ecology 20:257-271.

Apan A, Datt B, and Kelly R. 2005. Detection of pests and diseases in vegetable crops using hyperspectral sensing: a comparison of reflectance data for different sets of symptoms. Proceedings of the 2005 Spatial Sciences Institute Biennial Conference 2005: Spatial Intelligence, Innovation and Praxis (SSC2005): Spatial Sciences Institute. p 10-18.

Arbabtafti R, Sheikhigarjan A, Gharalari AH, and Damghani R. 2014. Effects of Adjuvants on the Efficacy of Certain Insecticides Against Ommatissus lybicus Bergevin (Hem.: Tropiduchidae) in Iran. Jordan Journal of Agricultural Sciences 10. 
880

881

882

883

884

885

886

887

888

889

890

891

892

893

894

895

896

897

898

899

900

901

902

903

904

905

906

907

908

909

910

911

912

913

914

915

916

917

Atzberger C. 2013. Advances in remote sensing of agriculture: Context description, existing operational monitoring systems and major information needs. Remote Sensing 5:949-981.

Bagheri A, Fathipour Y, Askari-Seyahooei M, and Zeinolabedini M. 2016. How Different Populations and Host Plant Cultivars Affect Two-Sex Life Table Parameters of the Date Palm Hopper, Ommatissus lybicus (Hemiptera: Tropiduchidae). Journal of Agricultural Science and Technology 18:16051619.

Bale JS, Masters GJ, Hodkinson ID, Awmack C, Bezemer TM, Brown VK, Butterfield J, Buse A, Coulson JC, and Farrar J. 2002. Herbivory in global climate change research: direct effects of rising temperature on insect herbivores. Global Change Biology 8:1-16.

Bedford GO, Al-Deeb MA, Khalaf MZ, Mohammadpour K, and Soltani R. 2015. Dynastid Beetle Pests. Sustainable Pest Management in Date Palm: Current Status and Emerging Challenges: Springer, 73-108.

Bishop M, and Colby J. 2002. Anisotropic reflectance correction of SPOT-3 HRV imagery. International Journal of Remote Sensing 23:2125-2131.

Blaschke T. 2010. Object based image analysis for remote sensing. ISPRS journal of photogrammetry and remote sensing 65:2-16.

Blumberg D. 2008. Review: Date palm arthropod pests and their management in Israel. Phytoparasitica 36:411-448.

Bonan GB. 1989. A computer model of the solar radiation, soil moisture, and soil thermal regimes in boreal forests. Ecological Modelling 45:275-306.

Bone C, Dragicevic S, and Roberts A. 2005. Integrating high resolution remote sensing, GIS and fuzzy set theory for identifying susceptibility areas of forest insect infestations. International Journal of Remote Sensing 26:4809-4828.

Boryan C, Yang Z, Mueller R, and Craig M. 2011. Monitoring US agriculture: the US department of agriculture, national agricultural statistics service, cropland data layer program. Geocarto International 26:341-358.

Bouyer J, Seck MT, Sall B, Ndiaye EY, Guerrini L, and Vreysen MJ. 2010. Stratified entomological sampling in preparation for an area-wide integrated pest management program: the example of Glossina palpalis gambiensis (Diptera: Glossinidae) in the Niayes of Senegal. Journal of medical entomology 47:543-552.

Burrough PA, and Frank A. 1996. Geographic objects with indeterminate boundaries: CRC Press.

Cammell M, and Knight J. 1992. Effects of climatic change on the population dynamics of crop pests. Advances in Ecological Research 22:117-162.

Cannon RJ. 1998. The implications of predicted climate change for insect pests in the UK, with emphasis on non-indigenous species. Global Change Biology 4:785-796.

Carrière Y, Ellsworth PC, Dutilleul P, Ellers-Kirk C, Barkley V, and Antilla L. 2006. A GIS-based approach for areawide pest management: the scales of Lygus hesperus movements to cotton from alfalfa, weeds, and cotton. Entomologia Experimentalis et Applicata 118:203-210. 
918 Carruthers RI. 2003. Invasive species research in the United States Department of Agriculture919 Agricultural Research Service. Pest management science 59:827-834.

920 Carter GA, and Knapp AK. 2001. Leaf optical properties in higher plants: linking spectral characteristics to stress and chlorophyll concentration. American Journal of Botany 88:677-684.

Castellana L, D'Addabbo A, and Pasquariello G. 2007. A composed supervised/unsupervised approach to improve change detection from remote sensing. Pattern Recognition Letters 28:405-413.

Chavez PS, and MacKinnon DJ. 1994. Automatic detection of vegetation changes in the southwestern United States using remotely sensed images. Photogrammetric Engineering and Remote Sensing 60 .

Colomina I, and Molina P. 2014. Unmanned aerial systems for photogrammetry and remote sensing: A

Congalton RG. 2001. Accuracy assessment and validation of remotely sensed and other spatial

932

933

934

Congalton RG, and Green K. 2008. Assessing the accuracy of remotely sensed data: principles and information. International Journal of Wildland Fire 10:321-328.

935 practices: CRC press. p.141-155.

Cook DC. 2008. Benefit cost analysis of an import access request. Food Policy 33:277-285.

936

937

938

939

Coops NC, Johnson M, Wulder MA, and White JC. 2006. Assessment of QuickBird high spatial resolution imagery to detect red attack damage due to mountain pine beetle infestation. Remote sensing of environment 103:67-80.

De Smith MJ, Goodchild MF, and Longley P. 2007. Geospatial analysis: a comprehensive guide to

Cox S. 2002. Information technology: the global key to precision agriculture and sustainability. Computers and Electronics in Agriculture 36:93-111.

Crooks AT, and Castle CJ. 2012. The integration of agent-based modelling and geographical information for geospatial simulation. Agent-based models of geographical systems: Springer, 219-251.

Dakshinamurti C, Krishnamurthy B, Summanwar A, Shanta P, and Pisharoty P. 1971. Remote sensing for coconut wilt. Proceedings of the seventh international symposium on remote sensing, Ann Arbor, MI. p 25-29.

Darvishzadeh R, Skidmore A, Schlerf M, Atzberger C, Corsi F, and Cho M. 2008. LAl and chlorophyll estimation for a heterogeneous grassland using hyperspectral measurements. ISPRS Journal of Photogrammetry and Remote Sensing 63:409-426.

Datt B, McVicar TR, Van Niel TG, Jupp DL, and Pearlman JS. 2003. Preprocessing EO-1 Hyperion hyperspectral data to support the application of agricultural indexes. IEEE Transactions on Geoscience and Remote Sensing 41:1246-1259. principles, techniques and software tools. p.69-82: Troubador Publishing Ltd.

Dey $\mathrm{V}$, Zhang $\mathrm{Y}$, and Zhong M. 2010. A review on image segmentation techniques with remote sensing perspective: p.31-42. 
956

957

958

959

960

961

962

963

964

965

966

967

968

969

970

971

972

973

974

975

976

977

978

979

980

981

982

983

984

985

986

987

988

989

990

991

992

993

994

dos Santos A, Oumar Z, Arnhold A, da Silva N, Oliveira Silva C, and Zanetti R. 2016. Multispectral characterization, prediction and mapping of Thaumastocoris peregrinus (Hemiptera: Thamascoridae) attack in Eucalyptus plantations using remote sensing. Journal of Spatial Science:1-11.

Drake A. 2002. Automatically operating radars for monitoring insect pest migrations. Insect Science 9:2739.

Drees C, Matern A, von Oheimb G, Reimann T, and Assmann T. 2010. Multiple glacial refuges of unwinged ground beetles in Europe: molecular data support classical phylogeographic models. Relict species: Springer, 199-215.

Dubayah R, and Rich PM. 1995. Topographic solar radiation models for GIS. International Journal of Geographical Information Systems 9:405-419.

Duda R, Hart P, and Stork D. 2001. Non-metric methods. Pattern classification 2:1-66.

Dupont J, Campanella R, and Seal M. 2000. Spatially variable insecticide applications through remote sensing. Proceedings of the Beltwide Cotton Conferences.

Eitel JU, Vierling LA, Litvak ME, Long DS, Schulthess U, Ager AA, Krofcheck DJ, and Stoscheck L. 2011. Broadband, red-edge information from satellites improves early stress detection in a New Mexico conifer woodland. Remote Sensing of Environment 115:3640-3646.

El-Haidari H, Mohammed I, and Daoud A. 1968. Evaluation of DDVP against the Dubas bug, Ommatissus binotatus libycus Berg., on date palms in Iraq (Hemiptera: Homoptera: Tropiduchidae). Bull Entomol Soc Egypt Econ Ser 2:91-94.

El-Juhany LI. 2010. Degradation of date palm trees and date production in Arab countries: causes and potential rehabilitation. Australian Journal of Basic and Applied Sciences 4:3998-4010.

El-Shafie H. 2012. Review: List of arthropod pests and their natural enemies identified worldwide on date palm, Phoenix dactylifera L. Agriculture and Biology Journal of North America 3:516-524.

Elwan A, and Al-Tamimi S. 1999. Life cycle of Dubas bug Ommatissus binotatus lybicus De Berg.(Homoptera: Tropiduchidae) in Sultanate of Oman. Egypt J Agric Res 77:1547-1553.

Feng H, Wu K, Cheng D, and Guo Y. 2003. Radar observations of the autumn migration of the beet armyworm Spodoptera exigua (Lepidoptera: Noctuidae) and other moths in northern China. Bulletin of entomological research 93:115-124.

Flint AL, and Childs SW. 1987. Calculation of solar radiation in mountainous terrain. Agricultural and forest meteorology 40:233-249.

Foody GM. 2002. Status of land cover classification accuracy assessment. Remote sensing of Environment 80:185-201.

Gassouma MS. 2004. Pests of the date palm (Phoenix dactylifera). Proceedings of the regional workshop on date palm development in the GCC countries of the Arabian Peninsula, Abu Dhabi, 29-31 May 2004.

Gebauer J, Luedeling E, Hammer K, Nagieb M, and Buerkert A. 2007. Mountain oases in northern Oman: an environment for evolution and in situ conservation of plant genetic resources. Genetic resources and crop evolution 54:465-481. 
995

996

997

998

999

1000

1001

1002

1003

1004

1005

1006

1007

1008

1009

1010

1011

1012

1013

1014

1015

1016

1017

1018

1019

1020

1021

1022

1023

1024

1025

1026

1027

1028

1029

1030

1031

1032

1033

Geiger M, Diabaté L, Ménard L, and Wald L. 2002. A web service for controlling the quality of measurements of global solar irradiation. Solar energy 73:475-480.

Gibbs HK, Ruesch AS, Achard F, Clayton MK, Holmgren P, Ramankutty N, and Foley JA. 2010. Tropical forests were the primary sources of new agricultural land in the 1980s and 1990s. Proceedings of the National Academy of Sciences 107:16732-16737.

Glenn EP, Huete AR, Nagler PL, and Nelson SG. 2008. Relationship between remotely-sensed vegetation indices, canopy attributes and plant physiological processes: what vegetation indices can and cannot tell us about the landscape. Sensors 8:2136-2160.

Goodchild MF. 1994. Integrating GIS and remote sensing for vegetation analysis and modeling: methodological issues. Journal of Vegetation Science 5:615-626.

Goodchild MF, and Glennon JA. 2010. Crowdsourcing geographic information for disaster response: a research frontier. International Journal of Digital Earth 3:231-241.

Gooshbor L, BAVAGHAR MP, Amanollahi J, and Ghobari H. 2016. Monitoring Infestations of Oak Forests by Tortrix viridana (Lepidoptera: Tortricidae) using Remote Sensing. Plant Protection Science 52.

Gorczyca W, Gong J, and Darzynkiewicz Z. 1993. Detection of DNA strand breaks in individual apoptotic cells by the in situ terminal deoxynucleotidyl transferase and nick translation assays. Cancer research 53:1945-1951.

Hall RJ, Skakun RS, and Arsenault EJ. 2006. Remotely sensed data in the mapping of insect defoliation. Understanding forest disturbance and spatial pattern: Remote sensing and GIS approaches:85111.

Haralick RM, and Shapiro LG. 1985. Image segmentation techniques. Computer vision, graphics, and image processing 29:100-132.

Harris P, Fotheringham A, Crespo R, and Charlton M. 2010. The use of geographically weighted regression for spatial prediction: an evaluation of models using simulated data sets. Mathematical Geosciences 42:657-680.

Harris R. 2003. Remote sensing of agriculture change in Oman. International Journal of Remote Sensing 24:4835-4852.

Hassan N. 2014. Biorational control strategies for important date palm pests. International Pest Control 56:92.

Hatfield P, and Pinter P. 1993. Remote sensing for crop protection. Crop protection 12:403-413.

Hernandez PA, Graham CH, Master LL, and Albert DL. 2006. The effect of sample size and species characteristics on performance of different species distribution modeling methods. Ecography 29:773-785.

Hetrick WA, Rich PM, Barnes FJ, and Weiss SB. 1993. GIS-based solar radiation flux models. ACSM ASPRS ANNUAL CONVENTION: AMERICAN SOC PHOTOGRAMMETRY \& REMOTE SENSING+ AMER CONG ON. p 132-132.

Hirano A, Welch R, and Lang H. 2003. Mapping from ASTER stereo image data: DEM validation and accuracy assessment. ISPRS Journal of Photogrammetry and Remote Sensing 57:356-370.

Howard F. 2001. Insect pests of palms and their control. Pesticide outlook 12:240-243. 
1034

1035

1036

1037

1038

1039

1040

1041

1042

1043

1044

1045

1046

1047

1048

1049

1050

1051

1052

1053

1054

1055

1056

1057

1058

1059

1060

1061

1062

1063

1064

1065

1066

1067

1068

1069

1070

Huang S, Liao Q, Hua M, Wu X, Bi K, Yan C, Chen B, and Zhang X. 2007. Survey of heavy metal pollution and assessment of agricultural soil in Yangzhong district, Jiangsu Province, China. Chemosphere 67:2148-2155.

Hughes ML, McDowell PF, and Marcus WA. 2006. Accuracy assessment of georectified aerial photographs: implications for measuring lateral channel movement in a GIS. Geomorphology 74:1-16.

Hussain AA. 1963. Biology and control of the dubas bug, Ommatissus binotatus lybicus De Berg.(Homoptera, Tropiduchidae), infesting date palms in Iraq. Bulletin of Entomological Research 53:737-745.

Hussein A, and Ali M. 1996. New records of the Dubas bug, Ommatissus binotatus lybicus de Berg., a threat to date palms in Bahria Oases. Egypt Bull Entomol Soci Egypt (ARE) 74:1-8.

Jadhav B, and Patil P. 2014. Hyperspectral Remote Sensing For Agricultural Management: A Survey. International Journal of Computer Applications 106.

Jasim H, and Al-Zubaidy H. 2010. Eggs Distribution of Old World Bug (Dubas Bug) Ommatissus lybicus (Derbeg) Asche and Wilson (Homoptera: Tropiduchidae) on Fronds Rows and Effect of Dust Storms on Three Varieties of Date Palm Trees. IV International Date Palm Conference 882. $p$ 465-470.

Jensen R. 2000. Agricultural volatility and investments in children. The American Economic Review 90:399-404.

Jhorar O, Mathauda S, Singh G, Butler D, and Mavi H. 1997. Relationships between climatic variables and Ascochyta blight of chickpea in Punjab, India. Agricultural and Forest Meteorology 87:171-177.

Jiang Z, Huete AR, Chen J, Chen Y, Li J, Yan G, and Zhang X. 2006. Analysis of NDVI and scaled difference vegetation index retrievals of vegetation fraction. Remote sensing of environment 101:366-378.

Justice C, Townshend J, Vermote E, Masuoka E, Wolfe R, Saleous N, Roy D, and Morisette J. 2002. An overview of MODIS Land data processing and product status. Remote sensing of Environment 83:3-15.

Karoui R, and Blecker C. 2011. Fluorescence spectroscopy measurement for quality assessment of food systems-a review. Food and Bioprocess technology 4:364-386.

Kaszab Z, Wittmer W, and Buttiker W. 1979. Insects of Saudi Arabia: Coleoptera: Fam. Tenebrionidae. Fauna of Saudi Arabia, Vol 1:257-288.

Kattenborn T, Sperlich M, Bataua K, and Koch B. 2014. Automatic Single Tree Detection in Plantations using UAV-based Photogrammetric Point clouds. The International Archives of Photogrammetry, Remote Sensing and Spatial Information Sciences 40:139.

Kaufman YJ, and Tanre D. 1992. Atmospherically resistant vegetation index (ARVI) for EOS-MODIS. IEEE Transactions on Geoscience and Remote Sensing 30:261-270.

Kerr JT, and Ostrovsky M. 2003. From space to species: ecological applications for remote sensing. Trends in Ecology \& Evolution 18:299-305. 
1071

1072

1073

1074

1075

1076

1077

1078

1079

1080

1081

1082

1083

1084

1085

1086

1087

1088

1089

1090

1091

1092

1093

1094

1095

1096

1097

1098

1099

1100

1101

1102

1103

1104

1105

1106

1107

1108

Khalaf MZ, and Khudhair MW. 2015. Spatial distribution of dubas bug, Ommatissus lybicus (Homoptera: Tropiduchidae) in date palm frond rows. International Journal of Entomological Research 3:0913.

Khalaf MZ, Shbar AK, Naher FH, Jabo NF, Abdulalhamza BH, and Sami RA. 2012. Activity of insect fauna during the night in the palm orchards of central Iraq. Journal of Food Science and Engineering 2:277-282.

Khudhair MW, Alrubeai HF, and Khalaf MZ. 2016. Innovative Method to Control Dubas Bug, Ommatissus lybicus (Deberg)(Homoptera: Tropiduchidae) in Date Palm Orchards Using Endophytic Beauveria bassiana Isolates.

Kirkpatrick J, and Nunez M. 1980. Vegetation-radiation relationships in mountainous terrain: eucalyptdominated vegetation in the Risdon Hills, Tasmania. Journal of Biogeography:197-208.

Klein M, and Venezian A. 1985. The dubas date Tropiduchid, Ommatissus binotatus lybicus, a threat to date palms in Israel. Phytoparasitica 13:95-101.

Kumar L, Skidmore AK, and Knowles E. 1997. Modelling topographic variation in solar radiation in a GIS environment. International Journal of Geographical Information Science 11:475-497.

Kwarteng AY, Dorvlo AS, and Vijaya Kumar GT. 2009. Analysis of a 27-year rainfall data (1977-2003) in the Sultanate of Oman. International Journal of Climatology 29:605-617.

Lamb D, and Brown R. 2001. Pa-precision agriculture: Remote-sensing and mapping of weeds in crops. Journal of Agricultural Engineering Research 78:117-125.

Lawrence R, and Labus M. 2003. Early detection of Douglas-fir beetle infestation with subcanopy resolution hyperspectral imagery. Western Journal of Applied Forestry 18:202-206.

Lawrence RL, and Wright A. 2001. Rule-based classification systems using classification and regression tree (CART) analysis. Photogrammetric engineering and remote sensing 67:1137-1142.

Leckie D, Jay C, Gougeon F, Sturrock R, and Paradine D. 2004. Detection and assessment of trees with Phellinus weirii (laminated root rot) using high resolution multi-spectral imagery. International Journal of Remote Sensing 25:793-818.

Lema J, Mendez R, and Blazquez R. 1988. Characteristics of landfill leachates and alternatives for their treatment: a review. Water, Air, and Soil Pollution 40:223-250.

Lenk S, Chaerle L, Pfündel EE, Langsdorf G, Hagenbeek D, Lichtenthaler HK, Van Der Straeten D, and Buschmann C. 2007. Multispectral fluorescence and reflectance imaging at the leaf level and its possible applications. Journal of Experimental Botany 58:807-814.

Leprieur C, Kerr Y, and Pichon J. 1996. Critical assessment of vegetation indices from AVHRR in a semiarid environment. Remote Sensing 17:2549-2563.

Li L-I, and Zhao H-y. 2007. Agricultural insect pests expert system based on case and fuzzy technology. Computer Engineering and Design 22:072.

Li Y, Huang G, Guo P, and Nie S. 2010. Interval-fuzzy possibilistic mixed integer linear programming for environmental management under uncertainty. International Journal of Environment and Pollution 42:107-124. 
1109

1110

1111

1112

1113

1114

1115

1116

1117

1118

1119

1120

1121

1122

1123

1124

1125

1126

1127

1128

1129

1130

1131

1132

1133

1134

1135

1136

1137

1138

1139

1140

1141

1142

1143

1144

1145

1146

1147

Liebhold AM, Rossi RE, and Kemp WP. 1993. Geostatistics and geographic information systems in applied insect ecology. Annual review of entomology 38:303-327.

Liu Z-Y, Wu H-F, and Huang J-F. 2010. Application of neural networks to discriminate fungal infection levels in rice panicles using hyperspectral reflectance and principal components analysis. Computers and Electronics in Agriculture 72:99-106.

Lookingbill T, and Urban D. 2004. An empirical approach towards improved spatial estimates of soil moisture for vegetation analysis. Landscape Ecology 19:417-433.

Loper GM. 1992. What do we really know about drone flight behaviour? Bee World 73:198-203.

Lu D, Mausel P, Brondizio E, and Moran E. 2004. Change detection techniques. International Journal of Remote Sensing 25:2365-2401.

Lu D, Moran E, and Batistella M. 2003. Linear mixture model applied to Amazonian vegetation classification. Remote sensing of Environment 87:456-469.

Lu D, and Weng Q. 2007. A survey of image classification methods and techniques for improving classification performance. International journal of remote sensing 28:823-870.

Luedeling E, and Buerkert A. 2008. Typology of oases in northern Oman based on Landsat and SRTM imagery and geological survey data. Remote Sensing of Environment 112:1181-1195.

Lunetta RS, Knight JF, Ediriwickrema J, Lyon JG, and Worthy LD. 2006. Land-cover change detection using multi-temporal MODIS NDVI data. Remote sensing of Environment 105:142-154.

Lyon JG, Yuan D, Lunetta RS, and Elvidge CD. 1998. A change detection experiment using vegetation indices. Photogrammetric Engineering and Remote Sensing 64:143-150.

Mahmoudi M, Sahragard A, Pezhman H, and Ghadamyari M. 2015. Demographic Analyses of Resistance of Five Varieties of Date Palm, Phoenix dactylifera L. to Ommatissus lybicus De Bergevin (Hemiptera: Tropiduchidae). Journal of Agricultural Science and Technology 17:263-273.

Mamoon A, Wright DJ, and Dobson H. 2016. Assessing the Optimum Droplet Size for Controlling Dubas Bug on Date Palm in the Sultanate of Oman When Applying an Insecticide Spray from an Aircraft. Outlooks on Pest Management 27:111-115.

Marx A, Sagischewski H, Sossna I, and Chmara S. 2010. Detecting bark beetle infestation in spruce stands using multi-temporal RapidEye Satellite Data. Forst und Holz 65:36-40.

Mavi H, Jhorar O, Sharma I, Singh G, Mahi G, Mathauda S, and Aujla S. 1992. Forecasting Karnal bunt disease of wheat-a meteorological method. Cereal Research Communications:67-74.

Mazza CA, Boccalandro HE, Giordano CV, Battista D, Scopel AL, and Ballaré CL. 2000. Functional significance and induction by solar radiation of ultraviolet-absorbing sunscreens in field-grown soybean crops. Plant physiology 122:117-126.

McFeeters SK. 1996. The use of the Normalized Difference Water Index (NDWI) in the delineation of open water features. International journal of remote sensing 17:1425-1432.

Menard S. 2002. Applied logistic regression analysis: Sage.

Mifsud D, Cocquempot C, Mühlethaler R, Wilson M, and Streito J-C. 2010. Other Hemiptera Sternorrhyncha (Aleyrodidae, Phylloxeroidea, and Psylloidea) and Hemiptera Auchenorrhyncha. Chapter 9.4. BioRisk 4:511. 
1148

1149

1150

1151

1152

1153

1154

1155

1156

1157

1158

1159

1160

1161

1162

1163

1164

1165

1166

1167

1168

1169

1170

1171

1172

1173

1174

1175

1176

1177

1178

1179

1180

1181

1182

1183

1184

1185

1186

Miles J, and Shevlin M. 2001. Applying regression and correlation: A guide for students and researchers: Sage.

Mokhtar A, and Al-Mjeini A. 1999. A novel approach to determine the efficacy control measures against Dubas bug Ommatissus lybicus de Berg on date palm. Agriculture Science 4:1-4.

Mokhtar AM, and Al Nabhani SS. 2010. Temperature-dependent development of dubas bug, Ommatissus lybicus (Hemiptera: Tropiduchidae), an endemic pest of date palm, Phoenix dactylifera. European Journal of Entomology 107:681.

Monteiro A, Souza Jr C, and Barreto P. 2003. Detection of logging in Amazonian transition forests using spectral mixture models. International journal of remote sensing 24:151-159.

Mountrakis G, Im J, and Ogole C. 2011. Support vector machines in remote sensing: A review. ISPRS journal of photogrammetry and remote sensing 66:247-259.

Munar-Vivas O, Morales-Osorio JG, and Castañeda-Sánchez DA. 2010. Use of field-integrated information in GIS-based maps to evaluate Moko disease (Ralstonia solanacearum) in banana growing farms in Colombia. Crop protection 29:936-941.

Nageswara Rao P, Ravishankar H, Raj U, and Nagajothi K. 2004. Production estimation of horticultural crops using irs-1d liss-iii data. Journal of the Indian Society of Remote Sensing 32:393-398.

Nebiker S, Annen A, Scherrer M, and Oesch D. 2008. A light-weight multispectral sensor for micro UAVOpportunities for very high resolution airborne remote sensing. The international archives of the photogrammetry, remote sensing and spatial information sciences 37:1193-1199.

Neteler M, Roiz D, Rocchini D, Castellani C, and Rizzoli A. 2011. Terra and Aqua satellites track tiger mosquito invasion: modelling the potential distribution of Aedes albopictus in north-eastern Italy. International Journal of Health Geographics 10:49.

Ortiz SM, Breidenbach J, and Kändler G. 2013. Early detection of bark beetle green attack using TerraSAR-X and RapidEye data. Remote Sensing 5:1912-1931.

Pao Y-H, and Sobajic DJ. 1992. Combined use of unsupervised and supervised learning for dynamic security assessment. IEEE Transactions on Power Systems 7:878-884.

Payandeh A, and Dehghan A. 2011. Life table parameters of the dubas bug, Ommatissus lybicus (Hem: Tropiduchidae) at three constant temperatures. African Journal of Biotechnology 10:1948919493.

Payandeh A, Kamali K, and Fathipour Y. 2010. Population structure and seasonal activity of Ommatissus Iybicus in Bam Region of Iran (Homoptera: tropiduchidae). Munis Entomol Zool 5:726-733.

Pinter Jr PJ, Hatfield JL, Schepers JS, Barnes EM, Moran MS, Daughtry CS, and Upchurch DR. 2003. Remote sensing for crop management. Photogrammetric Engineering \& Remote Sensing 69:647664.

Plant RE. 2001. Site-specific management: the application of information technology to crop production. Computers and Electronics in Agriculture 30:9-29.

Prabhakar M, Prasad Y, Thirupathi M, Sreedevi G, Dharajothi B, and Venkateswarlu B. 2011. Use of ground based hyperspectral remote sensing for detection of stress in cotton caused by leafhopper (Hemiptera: Cicadellidae). Computers and Electronics in Agriculture 79:189-198. 
1187

1188

1189

1190

1191

1192

1193

1194

1195

1196

1197

1198

1199

1200

1201

1202

1203

1204

1205

1206

1207

1208

1209

1210

1211

1212

1213

1214

1215

1216

1217

1218

1219

1220

1221

1222

1223

1224

1225

Pydipati R, Burks T, and Lee W. 2005. Statistical and neural network classifiers for citrus disease detection using machine vision. Transactions of the ASAE 48:2007-2014.

Reynolds A, Reynolds D, and Riley J. 2009. Does a 'turbophoretic'effect account for layer concentrations of insects migrating in the stable night-time atmosphere? Journal of The Royal Society Interface 6:87-95.

Reynolds D, and Riley J. 1997. Flight behaviour and migration of insect pests. Radar studies in developing countries: Natural Resources Institute (NRI).

Riley J. 1989. Remote sensing in entomology. Annual review of entomology 34:247-271.

Robertson C, Wulder M, Nelson T, and White J. 2008. Risk rating for mountain pine beetle infestation of lodgepole pine forests over large areas with ordinal regression modelling. Forest ecology and management 256:900-912.

Rogan J, Franklin J, and Roberts DA. 2002. A comparison of methods for monitoring multitemporal vegetation change using Thematic Mapper imagery. Remote sensing of Environment 80:143-156.

Rondeaux G, Steven M, and Baret F. 1996. Optimization of soil-adjusted vegetation indices. Remote sensing of environment 55:95-107.

Shafri HZ, and Hamdan N. 2009. Hyperspectral Imagery for Mapping Disease Infection in Oil Palm PlantationUsing Vegetation Indices and Red Edge Techniques. American Journal of Applied Sciences 6:1031-1135.

Shah A, Mohsin AU, Hafeez Z, Naeem M, and Haq MIU. 2013. Eggs Distribution Behaviour of Dubas Bug (Ommatissus Lybicus: Homoptera: Tropiduchidae) in Relation to Seasons and Some PhysicoMorphic Characters of Date Palm Leaves. Journal of insect behavior 26:371-386.

Shah A, Naeem M, Nasir MF, Irfan-ul-Haq M, and Hafeez Z. 2012. Biology of Dubas Bug, Ommatissus lybicus (Homoptera: Tropiduchidae), a Pest on Date Palm During Spring and Summer Seasons in Panjgur, Pakistan. Pakistan Journal of Zoology 44:1603-1611.

Shifley SR, Moser WK, Nowak DJ, Miles PD, Butler BJ, Aguilar FX, DeSantis RD, and Greenfield EJ. 2014. Five anthropogenic factors that will radically alter forest conditions and management needs in the northern United States. Forest Science 60:914-925.

Simone G, Farina A, Morabito FC, Serpico SB, and Bruzzone L. 2002. Image fusion techniques for remote sensing applications. Information fusion 3:3-15.

Song C, Woodcock CE, Seto KC, Lenney MP, and Macomber SA. 2001. Classification and change detection using Landsat TM data: when and how to correct atmospheric effects? Remote sensing of Environment 75:230-244.

Southwood T. 1978. Ecological methods: with particular reference to study of insect populations.p.348392.

Sperlich M, Kattenborn T, Koch B, and Kattenborn G. 2014. Potential of unmanned aerial vehicle based photogrammetric point clouds for automatic single tree detection. Available onlilne: http://www dgpf de/neu/Proc2014/proceedings/papers/Beitrag270 pdf (accessed on 15 January 2015).

Stafford JV. 2000. Implementing precision agriculture in the 21st century. Journal of Agricultural Engineering Research 76:267-275. 
1226

1227

1228

1229

1230

1231

1232

1233

1234

1235

1236

1237

1238

1239

1240

1241

1242

1243

1244

1245

1246

1247

1248

1249

1250

1251

1252

1253

1254

1255

1256

1257

1258

1259

1260

1261

1262

Stansbury C, and Pretorius Z. 2001. Modelling the potential distribution of Karnal bunt of wheat in South Africa. South African Journal of Plant and Soil 18:159-168.

Stephens M, Havlicek V, and Dakshinamurti K. 1971. Pyridoxine deficiency and development of the central nervous system in the rat. Journal of neurochemistry 18:2407-2416.

Swift LW. 1976. Algorithm for solar radiation on mountain slopes. Water Resources Research 12:108112.

Teillet P, Guindon B, and Goodenough D. 1982. On the slope-aspect correction of multispectral scanner data. Canadian Journal of Remote Sensing 8:84-106.

Teke M, Deveci HS, Haliloğlu O, Gürbüz SZ, and Sakarya U. 2013. A short survey of hyperspectral remote sensing applications in agriculture. Recent Advances in Space Technologies (RAST), 2013 6th International Conference on: IEEE. p 171-176.

Thacker J, Al-Mahmooli I, and Deadman M. 2003. Population dynamics and control of the dubas bug Ommatissus lybicus in the Sultanate of Oman. The BCPC International Congress: Crop Science and Technology, Volumes 1 and 2 Proceedings of an international congress held at the SECC, Glasgow, Scotland, UK, 10-12 November 2003: British Crop Protection Council. p 987-992.

Tobin PC, Parry D, and Aukema BH. 2014. The influence of climate change on insect invasions in temperate forest ecosystems. Challenges and Opportunities for the World's Forests in the 21st Century: Springer, 267-293.

Tremblay N, Wang Z, and Cerovic ZG. 2012. Sensing crop nitrogen status with fluorescence indicators. A review. Agronomy for sustainable development 32:451-464.

Vigier F, Coutanceau C, Hahn F, Belgsir E, and Lamy C. 2004. On the mechanism of ethanol electrooxidation on Pt and PtSn catalysts: electrochemical and in situ IR reflectance spectroscopy studies. Journal of Electroanalytical Chemistry 563:81-89.

Wang F, and Hall GB. 1996. Fuzzy representation of geographical boundaries in GIS. International journal of geographical information systems 10:573-590.

Westbrook J, and Isard S. 1999. Atmospheric scales of biotic dispersal. Agricultural and forest meteorology 97:263-274.

White EV, and Roy DP. 2015. A contemporary decennial examination of changing agricultural field sizes using Landsat time series data. Geo: Geography and Environment 2:33-54.

Wichmann L, and Ravn HP. 2001. The spread of Ips typographus (L.)(Coleoptera, Scolytidae) attacks following heavy windthrow in Denmark, analysed using GIS. Forest Ecology and Management 148:31-39.

Willers JL, Wu J, O'Hara C, and Jenkins JN. 2012. A categorical, improper probability method for combining NDVI and LiDAR elevation information for potential cotton precision agricultural applications. Computers and Electronics in Agriculture 82:15-22.

Wolter PT, Townsend PA, and Sturtevant BR. 2009. Estimation of forest structural parameters using 5 and 10 meter SPOT-5 satellite data. Remote Sensing of Environment 113:2019-2036. 
1263

1264

1265

1266

1267

1268

1269

1270

1271

1272

1273

1274

1275

1276

1277

1278

1279

1280

1281
Workneh F, Allen T, Nash G, Narasimhan B, Srinivasan R, and Rush C. 2008. Rainfall and temperature distinguish between Karnal bunt positive and negative years in wheat fields in Texas. Phytopathology 98:95-100.

Wulder MA, Dymond CC, White JC, Erickson B, Safranyik L, and Wilson B. 2006. Detection, mapping, and monitoring of the mountain pine beetle. The mountain pine beetle: $A$ synthesis of biology, management, and impacts on lodgepole pine Natural Resources Canada, Canadian Forest Service, Pacific Forestry Centre, Victoria, BC:123-154.

Zamani Z, Aminaee MM, and Khaniki GB. 2013. Introduction of Beauveria bassiana as a biological control agent against the Ommatissus lybicus in Kerman province. Archives of phytopathology and plant protection 46:1821-1830.

Zhang C, and Kovacs JM. 2012. The application of small unmanned aerial systems for precision agriculture: a review. Precision agriculture 13:693-712.

Zhang J, and Foody G. 2001. Fully-fuzzy supervised classification of sub-urban land cover from remotely sensed imagery: statistical and artificial neural network approaches. International Journal of Remote Sensing 22:615-628.

Zhang J, and Goodchild MF. 2002. Uncertainty in geographical information: CRC press.

Zwiggelaar R. 1998. A review of spectral properties of plants and their potential use for crop/weed discrimination in row-crops. Crop Protection 17:189-206. 